Check for updates

Cite this: RSC Adv., 2019, 9, 4210

Received 11th November 2018 Accepted 20th January 2019

DOI: $10.1039 / c 8 r a 09305 a$

rsc.li/rsc-advances

\section{Understanding the phyto-interaction of heavy metal oxide bulk and nanoparticles: evaluation of seed germination, growth, bioaccumulation, and metallothionein production $\dagger$}

Bilal Ahmed, (DD * Asfa Rizvi, Almas Zaidi, Mohammad Saghir Khan and Javed Musarrat:

The fast-growing use of nano-based products without proper care has led to a major public health concern. Nanomaterials contaminating the environment pose serious threat to the productivity of plants and via food chain to human health. Realizing these, four vegetable crops, radish, cucumber, tomato, and alfalfa, were exposed to varying concentrations of heavy metal oxide $\left(\mathrm{TiO}_{2}, \mathrm{ZnO}, \mathrm{Al}_{2} \mathrm{O}_{3}\right.$ and $\left.\mathrm{CuO}\right)$ submicron or bulk (BPs) and nanoparticles (NPs) to assess their impact on relative seed germination (RSG), seed surface adsorption, root/shoot tolerance index (RTI/STI), bioaccumulation, and metallothioneins (MTs) production. The results revealed a clear inhibition of RSG, RTI, and STI, which, however, varied between species of metal-specific nanoparticles and plants. SEM and EDX analyses showed significant adsorption of MONP agglomerates on seed surfaces. The concentration of metals detected by EDX differed among vegetables. Among the metals, $\mathrm{Al}, \mathrm{Cu}, \mathrm{Ti}$, and $\mathrm{Zn}$ were found maximum in alfalfa (12.46\%), tomato (23.2\%), cucumber (6.32\%) and radish (21.74\%). Of the four metal oxides, ZnO was found most inhibitory to all vegetables and was followed by $\mathrm{CuO}$. The absorption/accumulation of undesirable levels of MONPs in seeds and seedlings differed with variation in dose rates, and was found to be maximum (1748-2254 $\mathrm{g} \mathrm{g} \mathrm{g}^{-1}$ dry weight) in ZnO-NPs application. Among MONPs, the uptake of $\mathrm{TiO}_{2}$ was minimum ( 2 to $140 \mathrm{\mu g} \mathrm{g}^{-1}$ ) in radish seedlings. The concentration of MTs induced by $\mathrm{ZnO}-\mathrm{NPs}, \mathrm{ZnO}$ BPs, and CuO-NPs ranged between 52 and $136 \mu$ mol MTs $\mathrm{g}^{-1} \mathrm{FW}$ in vegetal organs. Conclusively, the present findings indicated that both the nanosize and chemical composition of MONPs are equally dangerous for vegetable production. Hence, the accumulation of MONPs, specifically $\mathrm{ZnO}$ and $\mathrm{CuO}$, in edible plant organs in reasonable amounts poses a potential environmental risk which, however, requires urgent attention to circumvent such toxic problems.

\section{Introduction}

Nano-technological advancements on the one hand have great potential in many environmental and industrial applications, while on the other hand they raise serious concerns over the use of NPs due to environmental problems. ${ }^{1}$ Among various NPs, metal oxide nanoparticles (MONPs) for example, $\mathrm{ZnO}, \mathrm{CuO}, \mathrm{TiO}_{2}$, $\mathrm{Al}_{2} \mathrm{O}_{3}, \mathrm{ZrO}_{2}, \mathrm{Fe}_{2} \mathrm{O}_{3}, \mathrm{Ag}_{2} \mathrm{O}, \mathrm{CeO}_{2}$ and $\mathrm{NiO}$ are widely used in many industries such as cosmetics, energy production, paints, textiles, and rocket fuels, and in biomedical applications., ${ }^{\mathbf{1} 2}$ Apart from these, MONPs have also been applied in agriculture practices as nano-fertilizers and in protecting plants from pathogens. ${ }^{3,4}$ Due

Department of Agricultural Microbiology, Faculty of Agricultural Sciences, Aligarh Muslim University, Aligarh 202002, U.P., India. E-mail: bilalahmed.amu@gmail. com; bilalahmed.rs@amu.ac.in; Tel: +91-9045836145

$\dagger$ Electronic supplementary information (ESI) available. See DOI: 10.1039/c8ra09305a

\$ Present address: School of Biosciences and Biodiversity, Baba Ghulam Shah Badshah University, Rajouri, J \& K, India. to the ever-increasing demands, it is likely that the production of MONPs which was just 0.27 million tons in 2012 will increase to 1.663 million tons by $2020 .^{5}$ Of the total production, $8-28 \%, 0.4-$ $7.0 \%$, and $0.1-1.5 \%$ MONPs are expected to accumulate in the soil system, water and atmosphere, respectively, after production, application, and discharge. ${ }^{5}$ Once deposited in soil either through nano-products such as fertilizers, insecticide, and pesticides ${ }^{\mathbf{1 , 4}}$ or from other sources, the MONPs may become toxic to bacteria, plants, animal, and human cells. ${ }^{6-9}$ Despite these, the understanding on lethality of MONPs is still limited and hence, requires special attention to better understand the consequences of MONPs on crop production..$^{10}$ However, in this context, a very few attempts have been made to assess the biological impacts of NPs in controlled laboratory conditions with single species of model organisms, which are essential to elucidate the interaction mechanism of NPs. ${ }^{11}$

Indeed, plants are critical for the sustenance of the ecosystem, and due to the direct association of roots with soil ecosystem, plants come in direct contact with soil constituents 
either present naturally or deposited anthropogenically. ${ }^{12}$ Among anthropogenic materials, the MONPs penetrate plant cells either through the process of endocytosis or by other transport systems and are bioaccumulated inside plant tissues. ${ }^{5}$ However, the uptake, translocation, and bioaccumulation of MONPs in plants depend upon the size, chemical composition and shape of the MONPs and plant anatomy. ${ }^{13,14}$ Following accumulation, they cause morpho-biochemical changes in plants. ${ }^{10}$ For example, $\mathrm{ZnO}-\mathrm{NPs}, \mathrm{TiO}_{2}$-NPs, $\mathrm{Al}_{2} \mathrm{O}_{3}$-NPs, CuO-NPs, NiO-NPs, CdO-NPs, and $\mathrm{Fe}_{2} \mathrm{O}_{3}$-NPs have been found accumulated in plant tissues and are reported to be toxic to major agriculture crops such as soybean, corn, cucumber, tomato, wheat, maize, mung, bean, chickpea, spinach, and barley. ${ }^{1,5,15}$ However, there are only few reports on the assessment of the effect of a single type of MONPs on different plant species under identical growth environment. For instance, García-Gómez et al. reported the comparative phytotoxicity of ZnO-NPs on nine crops grown in calcareous and acidic soil. ${ }^{10}$ The study suggested that plant species and soil $\mathrm{pH}$ were key factors affecting the availability of $\mathrm{Zn}$ and toxicity of ZnO-NPs. In yet another study, the toxicity of various MONPs such as $\mathrm{CuO}, \mathrm{Al}_{2} \mathrm{O}_{3}, \mathrm{MnO}, \mathrm{Fe}_{3} \mathrm{O}_{4}$, $\mathrm{ZnO}$, and $\mathrm{TiO}_{2}$ was tested against germinating seeds of Sinapis alba. ${ }^{13}$ Among MONPs, $\mathrm{Al}_{2} \mathrm{O}_{3}, \mathrm{MnO}, \mathrm{Fe}_{3} \mathrm{O}_{4}$, and $\mathrm{TiO}_{2}$ did not affect seed germination, while ZnO-NPs and CuO-NPs inhibited germination in a dose-dependent manner. Interestingly, like metals, the varying impact of NPs on different plant species also depends on the size, concentration, duration of exposure, plant genotypes and experimental conditions. ${ }^{16}$ The different thresholds of NP toxicity in plants in different experimental setups may further complicate the classification of plants into tolerant or sensitive groups. This situation demands the examination of nano-phytotoxicity among different plant species. Therefore, in our study we exposed four vegetable crops including radish (Raphanus sativus), cucumber (Cucumis sativus), tomato (Solanum lycopersicon), and alfalfa (Medicago sativa) to varying levels of four MONPs $\left(\mathrm{ZnO}, \mathrm{CuO}, \mathrm{TiO}_{2}\right.$, and $\mathrm{Al}_{2} \mathrm{O}_{3}$ NPs) along with their bulk counterparts (BPs) to explain the following - (i) adsorption of heavy MONPs on seeds and relative seed germination, (ii) root and shoot tolerance index, (iii) uptake of metal by seeds and seedlings, and (iv) MTs production under stress. The four vegetables used in this study were intentionally chosen to assess the phyto-interaction of four MONPs, $\mathrm{ZnO}, \mathrm{Al}_{2} \mathrm{O}_{3}, \mathrm{TiO}_{2}$, and $\mathrm{CuO}$ largely due to their high demand in human dietary system. Also, these vegetables, are reported to respond well to $\mathrm{NPs}$ such as $\mathrm{Ag}, \mathrm{Ni}, \mathrm{CeO}_{2}, \mathrm{ZnO}$, and $\mathrm{Fe}_{3} \mathrm{O}_{4}{ }^{1,15}$ Apart from these, submicron- and nano-forms of metal oxides of $\mathrm{Cu}, \mathrm{Al}, \mathrm{Zn}$, and Ti were selected keeping in mind their use in various industrial products including explosives, alloys, drug delivery tools, personal care products, catalysts, sensors, semiconductor devices, batteries, microelectronics, antimicrobial coatings, textiles, paints and food containers. ${ }^{2,4,5,13}$ When discharged into the environment without proper treatment, such MONPs destruct the very sustainability of agro-eco systems. ${ }^{15}$ Due to these and several other reasons, four MONPs were selected to evaluate their nano-phyto-interaction activity against popularly grown vegetables worldwide.

\section{Materials and methods}

\subsection{Nanoparticles, bulk particles and their characterization}

The MONPs namely, ZnO-NPs (product code 2640103), CuONPs (product code 2040263), $\mathrm{TiO}_{2}$-NPs (product code 28954), and $\mathrm{Al}_{2} \mathrm{O}_{3}$-NPs (product code 75364) purchased from Sisco Research Laboratories (Mumbai, India) were thoroughly characterized (please see ESI $\dagger$ ). Before application, NPs were ultrasonicated at $60 \%$ amplitude for $30 \mathrm{~min}$ in double distilled water (DDW) in an ice bath.

\subsection{Seedling growth and exposure conditions}

The outline of the assessment of heavy MONPs in agricultural crops is presented in Fig. 1. Healthy seeds of R. sativus var. Meena early, C. sativus var. Karina, S. lycopersicon var. NP-7715 and M. sativa var. Chetak S-244 were properly sterilized using $2 \%$ solution of sodium hypochlorite ( $\mathrm{NaOCl}$ ) for $10 \mathrm{~min}$. Seeds were exposed to NPs and BPs of $\mathrm{TiO}_{2}, \mathrm{ZnO}, \mathrm{Al}_{2} \mathrm{O}_{3}$, and $\mathrm{CuO}$ in two sets of experiments - (i) seeds $(N=30)$ from each plant species were soaked in $0.05,0.5,2$, and $5 \mathrm{mg} \mathrm{ml}^{-1}$ of NPs and BPs prepared in DDW for $12 \mathrm{~h}$ and kept on a rotatory shaker (150 rpm) at $25 \pm 2{ }^{\circ} \mathrm{C}$. Subsequently, seeds were rinsed with DDW and transferred to semi solid agar $(0.4 \%)$ medium mixed with modified composition of $1 / 4$ Hoagland nutrient medium ${ }^{12}$ maintaining $\geq 1 \mathrm{~cm}$ distance among seeds. (ii) Sterilized seeds $(N=10)$ were directly transferred on to semi-solid $(0.4 \%)$ Hoagland $1 / 4$ nutrient agar media in Petri dishes $(100 \times 20$ $\mathrm{mm}$ ) supplemented with $0.05,0.5,2$, and $5 \mathrm{mg} \mathrm{ml}^{-1}$ of NPs/BPs of $\mathrm{TiO}_{2}, \mathrm{ZnO}, \mathrm{Al}_{2} \mathrm{O}_{3}$, and $\mathrm{CuO}$. Petri dishes containing seeds were then placed in a growth chamber at $25 \pm 2{ }^{\circ} \mathrm{C}$ for germination and allowed to grow further. Each individual experiment was repeated three times.

\subsection{Adsorption of NPs on plant seeds}

Localized NPs of $\mathrm{TiO}_{2}, \mathrm{ZnO}, \mathrm{Al}_{2} \mathrm{O}_{3}$, and $\mathrm{CuO}$ on seed surface were analyzed by SEM and EDX spectroscopy. Seeds dipped in MONPs were continuously stirred at $150 \mathrm{rpm}$ in order to avoid the sedimentation of MONPs at the bottom of the flasks. Seeds exposed to $2 \mathrm{mg} \mathrm{ml}^{-1}$ concentration of each of the NPs were rinsed with sterile DDW and fixed in $2.5 \%$ glutaraldehyde and $2 \%$ paraformaldehyde in $0.1 \mathrm{M}$ sodium phosphate buffer $(\mathrm{pH}$ 7.2) for $2 \mathrm{~h}$ at room temperature and at $4{ }^{\circ} \mathrm{C}$ for $6 \mathrm{~h}$ with intermittent vortexing. After three rinses with $0.1 \mathrm{M}$ sodium phosphate buffer ( $\mathrm{pH}$ 7.2), the seeds were dehydrated in a gradient of ethanol ranging from $30 \%$ to $100 \%$ for $10 \mathrm{~min}$ in each. The dehydrated seeds were then processed for SEM and EDX analysis (please see ESI†).

\subsection{Analysis of growth parameters}

Percent seed germination and root and shoot tolerance index (\%) were measured for all replicates in dark at $25 \pm 2{ }^{\circ} \mathrm{C}$ after 4 days of $R$. sativus growth, 7 days of M. sativa growth, and after 6 days each of $C$. sativus and S. lycopersicon growth. A seed was considered germinated after the emergence of plumule or 


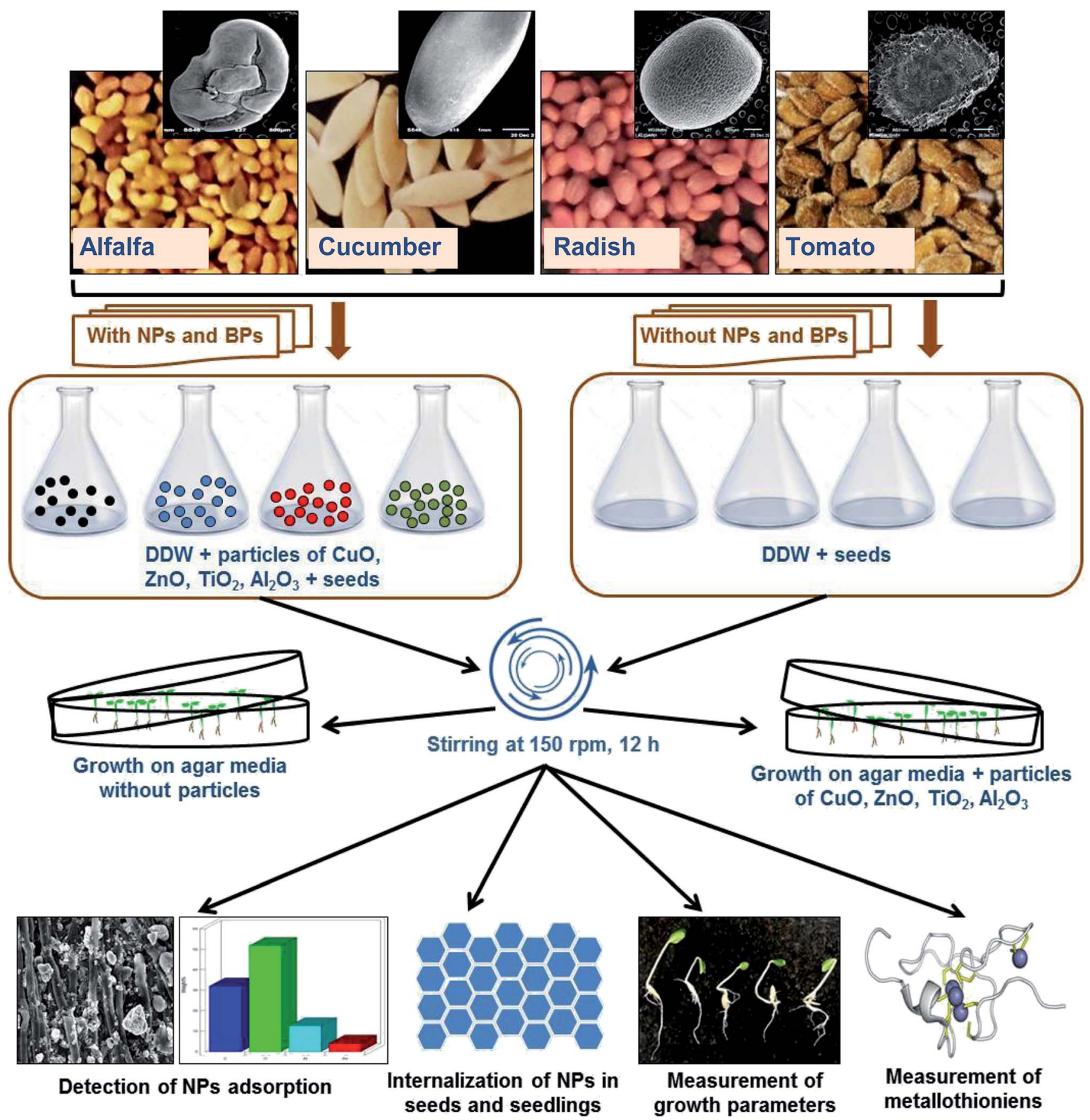

Fig. 1 Experimental outline of the assessment of MONPs in alfalfa, cucumber, radish, and tomato plants

radicles from the seed coat. From the data obtained, three calculations were made:

Relative seed germination $(\mathrm{RSG})(\%)$

$=\frac{\text { Average germination of treated seeds }}{\text { Average germination of control seeds }} \times 100$

Root tolerance index $(\mathrm{RTI})(\%)$

$=\frac{\text { Average root length of treated seedlings }(\mathrm{cm})}{\text { Average root length of control seedlings }(\mathrm{cm})} \times 100$

(2) To estimate the amount of $\mathrm{TiO}_{2}, \mathrm{ZnO}, \mathrm{Al}_{2} \mathrm{O}_{3}$, and $\mathrm{CuO}$ NPs deposited in R. sativus, C. sativus, S. lycopersicon, and M. sativa, 

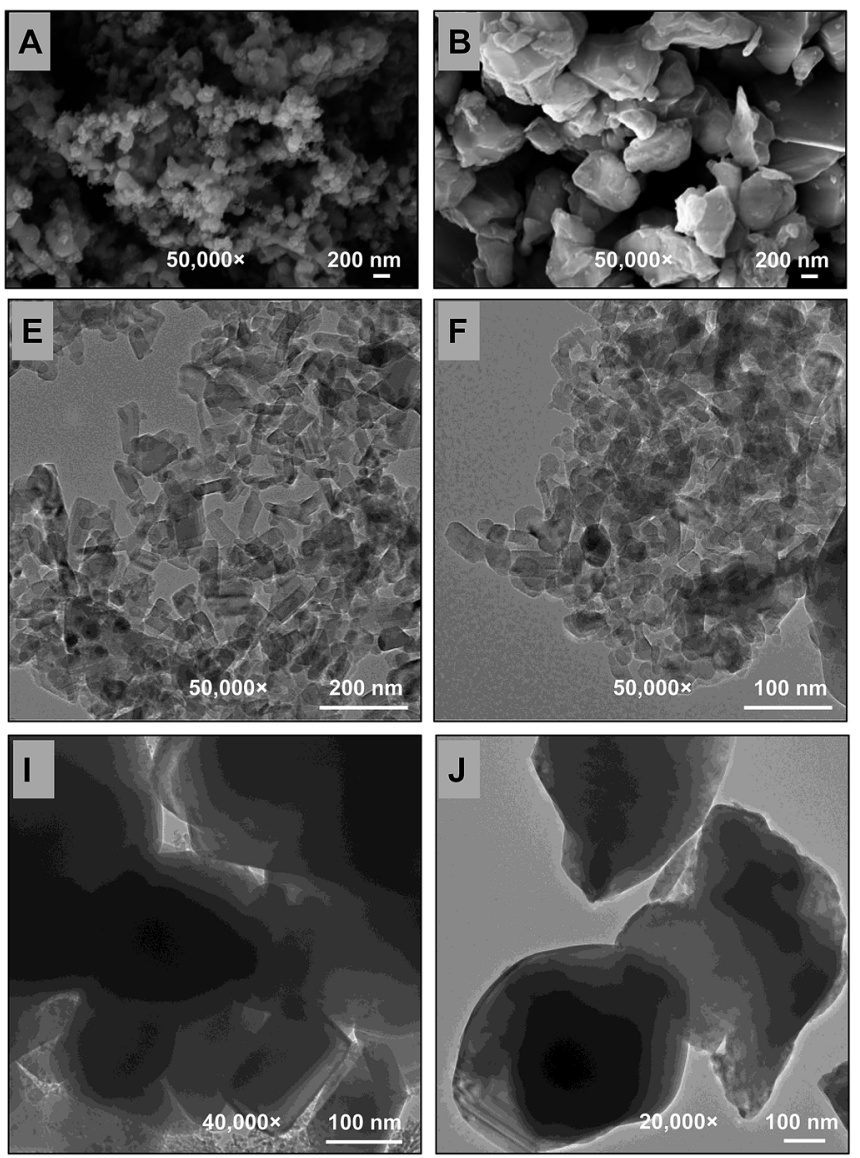
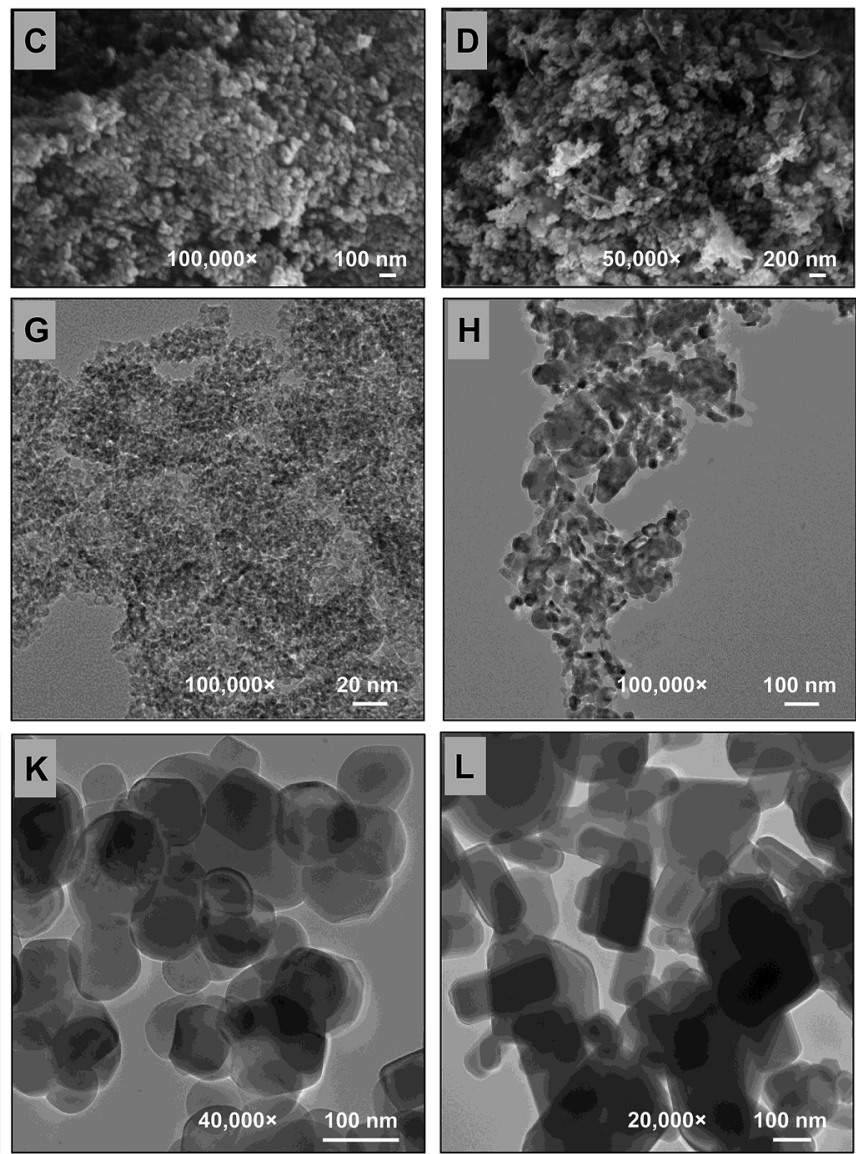

Fig. 2 SEM (A-D) and TEM micrographs of NPs (E-H) and BPs (I-L): $\mathrm{Al}_{2} \mathrm{O}_{3}-\mathrm{NPs}(\mathrm{A}$ and $\mathrm{E}), \mathrm{CuO}-\mathrm{NPs}(\mathrm{B}$ and $\mathrm{F}), \mathrm{TiO}{ }_{2}-\mathrm{NPs}(\mathrm{C}$ and $\mathrm{G}), \mathrm{ZnO}-\mathrm{NPs}(\mathrm{D}$ and $\mathrm{H}$ ), $\mathrm{Al}_{2} \mathrm{O}_{3}-\mathrm{BPs}(\mathrm{I}), \mathrm{CuO}-\mathrm{BPs}(\mathrm{J}), \mathrm{TiO}_{2}-\mathrm{BPs}(\mathrm{K})$, and $\mathrm{ZnO}-\mathrm{BPs}(\mathrm{L})$.

seeds (after soaking for $12 \mathrm{~h}$ ) and germinated seedlings from treated and control groups were allowed to dry at $60^{\circ} \mathrm{C}$ for $24 \mathrm{~h}$. The dried biomass was further processed (please see ESI $\dagger$ ).

\subsection{Extraction and measurement of metallothioneins}

Sterilized seeds of radish, cucumber, tomato and alfalfa with and without soaking in NP solutions and grown in the absence and presence of $0.05,0.5,2$, and $5 \mathrm{mg} \mathrm{ml}^{-1}$ of $\mathrm{Al}_{2} \mathrm{O}_{3}-\mathrm{NPs}$, CuO$\mathrm{NPs}, \mathrm{TiO}_{2}$-NPs and ZnO-NPs, respectively, were incubated on soft agar medium for 10 days in dark at $25{ }^{\circ} \mathrm{C}$ and allowed to grow. Thereafter, the roots emerging from the experimental plants were detached and washed to remove adhering particles. The seedlings treated with $200 \mu \mathrm{M} \mathrm{Cu}^{2+}$ served as the positive control. A total of $0.5 \mathrm{~g}$ root tissue was crushed in extraction buffer (pH 8.0) containing $0.7 \mathrm{M}$ sucrose, $0.5 \mathrm{M}$ tris, $50 \mathrm{mM}$ EDTA, $0.1 \mathrm{M} \mathrm{KCl}$, and $1 \mathrm{mM}$ phenylmethyl sulfonyl fluoride (PMSF). To this, $\beta$-mercaptoethanol ( $\beta$-ME) was added just before the extraction process maintaining $0.01 \% \beta$-ME in the extraction buffer. The tissues were sonicated for $2 \min (30 / 30$ seconds pulse on/off) at $40 \%$ amplitude in ice bath. The sonicated samples were centrifuged at $8000 \mathrm{rpm}$ for $30 \mathrm{~min}$ at $4{ }^{\circ} \mathrm{C}$ to obtain a supernatant containing metallothionein. A total of $2 \mathrm{ml}$ of the resulting supernatant was mixed with $2 \mathrm{ml}$ prechilled ethanol and $80 \mu \mathrm{l}$ chloroform and vortexed. The samples were centrifuged in cold $\left(0-4^{\circ} \mathrm{C}\right)$ at $5000 \mathrm{rpm}$ for $5 \mathrm{~min}$ and three volumes of pre-chilled ethanol was added to the resulting supernatant and kept at $-20{ }^{\circ} \mathrm{C}$ for at least $1 \mathrm{~h}$. The pellet was spun again in cold $\left(0-4{ }^{\circ} \mathrm{C}\right)$ at $5000 \mathrm{rpm}$ for $5 \mathrm{~min}$, and the pellets were washed with a mixture of ethanol :chloroform : homogenization buffer $(0.7 \mathrm{M}$ sucrose, $0.5 \mathrm{M}$ tris, pH 8.0 containing $\beta$-ME $0.01 \%)$ in the ratio of $87: 1: 12$. The pellets were air dried and re-suspended in $500 \mu \mathrm{l}$ of $5 \mathrm{mM}$ tris and $1 \mathrm{mM}$ EDTA mixture at $\mathrm{pH}$ 7. To this fraction of MTs, $4.2 \mathrm{ml}$ of $0.43 \mathrm{mM}$ Ellman's reagent $\left(5,5^{\prime}\right.$-dithiobis-(2-nitrobenzoic acid)) in $0.2 \mathrm{M}$ potassium phosphate buffer was added at $\mathrm{pH} 8$ and incubated at room temperature for $30 \mathrm{~min}$. The absorbance was recorded at $412 \mathrm{~nm}$ to estimate the concentration of reduced sulfhydryl (-SH). A standard linear curve of reduced glutathione was run in parallel from $13.33-133.3 \mu \mathrm{M}$ at $412 \mathrm{~nm}$ $\left(r^{2}=0.98\right)$ (ESI Fig. $\left.1 \dagger\right)$. The GSH containing one cysteine per molecule serves as reference for quantifying cysteines in protein. The amount of MTs in the samples was calculated assuming that $1 \mathrm{~mol}$ of MT contains $20 \mathrm{~mol}$ of cysteine. The MTs in the samples were measured using the standard curve of reduced glutathione (GSH).

\subsection{Statistical analysis}

All experiments were performed three times and statistical significance was calculated at 95\% confidence limit $(P \leq 0.05)$. Microsoft Excel (2016) and Sigma plot 10.0 were used to prepare 
curves and graphs. Statistical analyses were performed using one-way analysis of variance (ANOVA) using statistical software Minitab 17 (Minitab Inc., State College PA, USA).

\section{Results and discussion}

\subsection{Characterization of NPs and BPs}

The surface morphology, average crystalline size and shape of MONPs were observed under XRD (ESI Fig. 2a-d $\dagger$ ), FTIR (ESI Fig. 3a-d $\dagger$ ), SEM (Fig. 2a-d), EDX (ESI Fig. 4a-d $\dagger$ ), TEM (Fig. 2eh), 2D-AFM (ESI Fig. 5a-d $\dagger$ ) and 3D-AFM (ESI Fig. 5e-h†). The XRD pattern of MONPs ranged between 20 and 80 degree of $2 \theta$ values and were found similar to JCPDS file no. 77-2135, 450937, 78-2486, and 36-1451 for $\mathrm{Al}_{2} \mathrm{O}_{3}$-NPs (ESI Fig. 2a†), CuONPs (ESI Fig. 2b $\dagger$ ), $\mathrm{TiO}_{2}$-NPs (ESI Fig. 2c $\dagger$ ), and ZnO-NPs (ESI Fig. $2 \mathrm{~d} \dagger)$, respectively. The percent frequency size distribution of MONPs is shown in ESI Fig. 6a-d. $\dagger$ The SEM (Fig. 2a-d) and AFM (ESI Fig. 5a-h $\dagger$ ) micrographs exhibited the topography and surface characteristic of MONPs, which indicated the presence of variable size aggregates of MONPs (Table 1). The FTIR data showed the characteristic metal-oxide (M-O) bond for all MONPs, which was found at 466, 533, 541, and $482 \mathrm{~cm}^{-1}$ for $\mathrm{Al}_{2} \mathrm{O}_{3}$-NPs, CuO-NPs, $\mathrm{TiO}_{2}$-NPs, and ZnO-NPs, respectively. The characteristics of the MONPs used in this study are presented in detail in Table 1. The average sizes of the $\mathrm{BPs}$ of $\mathrm{Al}_{2} \mathrm{O}_{3}$ (Fig. 2i), $\mathrm{CuO}$ (Fig. 2j), $\mathrm{TiO}_{2}$ (Fig. 2k), and $\mathrm{ZnO}$ (Fig. 2l) measured by TEM were $167,586,144$, and $240 \mathrm{~nm}$, respectively.

\subsection{Adsorption of heavy MONPs on seeds}

The deposition of MONPs on the seed surface of radish, cucumber, tomato and alfalfa was detected by SEM equipped EDX after uniform shaking of seeds in an aqueous dispersion of MONPs. The data obtained are shown in Fig. 3 and 4. The SEM images represent the region of interest (ROI) on the seed surface for which the EDX spectrum was obtained from individual treatment. The weight percentage of different elements detected in EDX spectra is shown in the inset of each EDX spectrum as bars. Small and large aggregates of variable sizes were noticed on seed surfaces treated with $\mathrm{Al}_{2} \mathrm{O}_{3}$-NPs (Fig. 3m-t), CuO-NPs (Fig. 4a-h), TiO $_{2}$-NPs (Fig. 4i-p), and ZnO-NPs (Fig. $4 \mathrm{q}-\mathrm{x}$ ). In contrast, the surface of seeds in the control group was clear and no heavy metal signal was obtained
(Fig. 3a-l). Besides for $\mathrm{C}$ and $\mathrm{O}$, signals for $\mathrm{Au}$ (Fig. 3i, n, p, r and t) and $\mathrm{Na}$ (Fig. 3i, r and t) were also noticed in some samples. The signals for $\mathrm{Au}$ might have come from the gold sputter coating done before SEM analysis, whereas, Na was one of the constituents of the phosphate buffer used for washing the seeds. The weight of metals expressed in percentage value as detected by EDX followed the order - (i) Al: 12.46, 7.66, 2.25, 3.59 (ii) Cu: 13.97, 6.90, 2.31, 23.20, (iii) Ti: 1.36, 6.32, 2.06, 3.84, and (iv) Zn: 17.13, 5.48, 21.74, 17.37 for the seeds of alfalfa, cucumber, radish, and tomato, respectively. The adsorption of NPs on seed coating is likely to cause toxicity to the growing vegetables.

\subsection{Effect of NPs and BPs on relative seed germination}

Seed germination is indeed the first stage toward the successful establishment of crops. The germination of seeds has therefore been widely used as an index to assay the phytotoxicity of agrochemicals. ${ }^{17}$ Seed germination and root and shoot tolerance index of alfalfa, cucumber, radish and tomato, grown with and without NPs and BPs, varied considerably among the vegetables and under different MONP concentrations (Fig. 5-8). The impact of MONPs/BPs on four popularly grown vegetables is discussed in the following sections.

3.3.1 Radish (R. sativus). Generally, the RSG of the four vegetables declined gradually with consequent increase in the concentration of MONPs. For example, none of the MONPS exhibited any obvious toxic effects on the RSG of radish grown under both experimental setups (Fig. 5a, d, g and j). In contrast, on Hoagland's agar medium supplemented with 0.05 and $2 \mathrm{mg}$ $\mathrm{ml}^{-1} \mathrm{TiO}_{2}$-NPs, the RSG was significantly $(P \leq 0.01)$ reduced by $25 \%$ and $26 \%$, respectively (Fig. 5a). Similarly, the aqueous dispersions of ZnO-NPs declined the RSG maximally by $27 \%$ at $5 \mathrm{mg} \mathrm{m}{ }^{-1}$ while ZnO-BPs inhibited the RSG maximally and significantly ( $P \leq 0.01$ ) by $30 \%$ at $5 \mathrm{mg} \mathrm{ml}^{-1}$ (Fig. $5 \mathrm{~d}$ ). The $\mathrm{Al}_{2} \mathrm{O}_{3}$ NPs at 0.5 and $2 \mathrm{mg} \mathrm{ml}^{-1}$ and $\mathrm{Al}_{2} \mathrm{O}_{3}$-BPs at 2 and $5 \mathrm{mg} \mathrm{ml}^{-1}$ reduced the RSG by $9-17 \%$ and $10 \%$, respectively (Fig. $5 \mathrm{~g}$ ). A trend similar to $\mathrm{TiO}_{2}$-NPs was also obtained for CuO-NPs (Fig. 5j). None of the CuO-BPs concentrations, however, altered the RSG of radish.

3.3.2 Cucumber (C. sativus). In cucumber, raised on supplemented agar, $\mathrm{TiO}_{2}$-NPs at $0.05 \mathrm{mg} \mathrm{ml}^{-1}$ enhanced the RSG by $11 \%$ over control and after soaking with $2 \mathrm{mg} \mathrm{ml}^{-1}$, it enhanced

Table 1 Characteristics of heavy MONPs assessed in radish, cucumber, tomato, and alfalfa plants

\begin{tabular}{lllll}
\hline Particulars & $\mathrm{Al}_{2} \mathrm{O}_{3}$-NPs & CuO-NPs & TiO $_{2}$-NPs & ZnO-NPs \\
\hline Size on packing $(\mathrm{nm})$ & $20-30$ & $\approx 40$ & $\approx 7$ & $\approx 30$ \\
Assay, min $(\%)$ & 99.9 & 99 & 95 & 99.9 \\
Elemental\% in EDX & $\mathrm{Al}(50.61), \mathrm{O}(49.39)$ & $\mathrm{Cu}(76.7), \mathrm{O}(23.3)$ & $\mathrm{Ti}(53.19), \mathrm{O}(46.81)$ & $\mathrm{Zn}(78.92), \mathrm{O}(21.08)$ \\
spectrum & & & \\
Morphology by SEM, AFM, & Spherical to lobular to short Irregular individuals and & Spherical with uniform size & Pleomorphic, smaller to \\
and TEM & rods of variable length and & aggregates with rough & distribution & larger sized aggregates with \\
& diameter & surface & & some small thin sheets \\
Crystal size by XRD (nm) & 28 & 18 & 4 & 24 \\
Primary size by TEM (nm) & $21.8 \pm 8.7$ & $18.4 \pm 5.5$ & $3.9 \pm 0.9$ & $34 \pm 10$ \\
Secondary size by QLS (nm) & $238 \pm 4.6$ & $194 \pm 5.8$ & $148 \pm 8.4$ & $248 \pm 11.7$ \\
Zeta potential $(\mathrm{mV})$ & $+26.1 \pm 1.7$ & $-29.8 \pm 2.1$ & $+19.2 \pm 2.3$ & $-21 \pm 0.9$ \\
Signal in IR spectrum $\left(\mathrm{cm}^{-1}\right)$ & 466 & 533 & 541 & 482
\end{tabular}



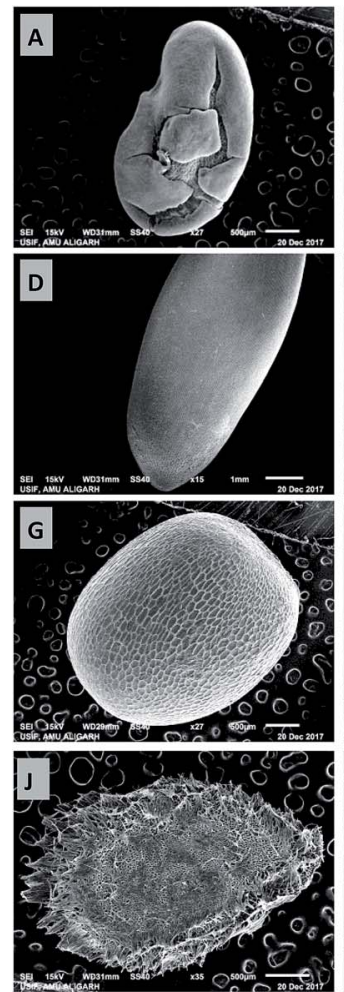
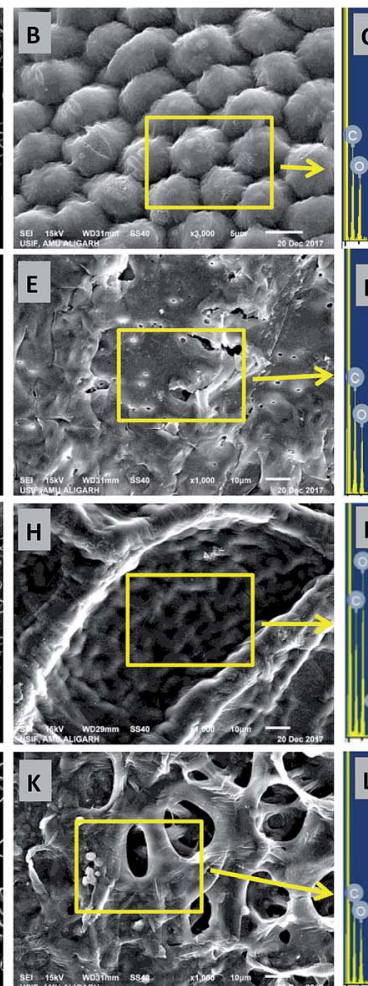
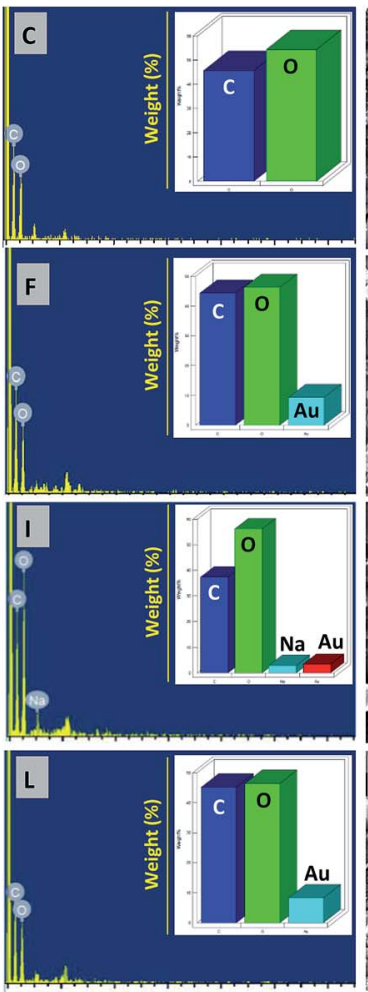
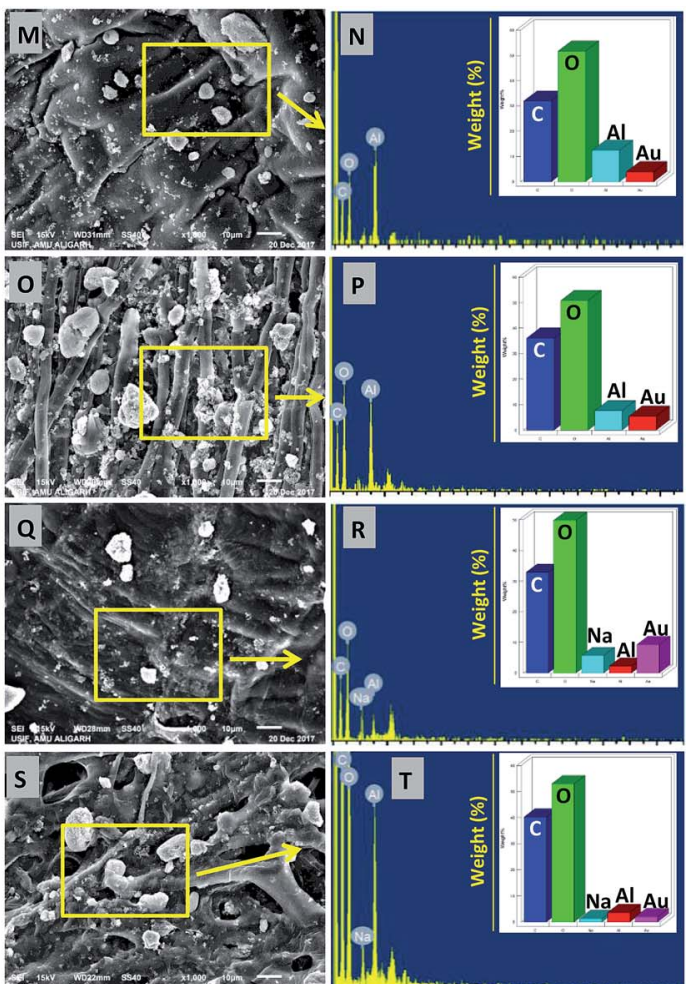

Fig. 3 SEM and EDX-based analysis of untreated seeds of M. sativa (A-C), C. sativus (D-F), R. sativus (G-I), and S. lycopersicon (J-L). Panels (MT) show the adsorption of $\mathrm{Al}_{2} \mathrm{O}_{3}-\mathrm{NPs}$ and their detection by EDX on the surface of $M$. sativa $(\mathrm{M}-\mathrm{N}), \mathrm{C}$. sativus $(\mathrm{O}-\mathrm{P}), \mathrm{R}$. sativus $(\mathrm{Q}-\mathrm{R})$, and $\mathrm{S}$. lycopersicon (S-T) seeds after exposure to $\mathrm{Al}_{2} \mathrm{O}_{3}-\mathrm{NPs}$ in water for $12 \mathrm{~h}$. EDX spectra showed metal peaks and weight percentage of different elements (N, $\mathrm{P}, \mathrm{R}$, and $\mathrm{T})$.
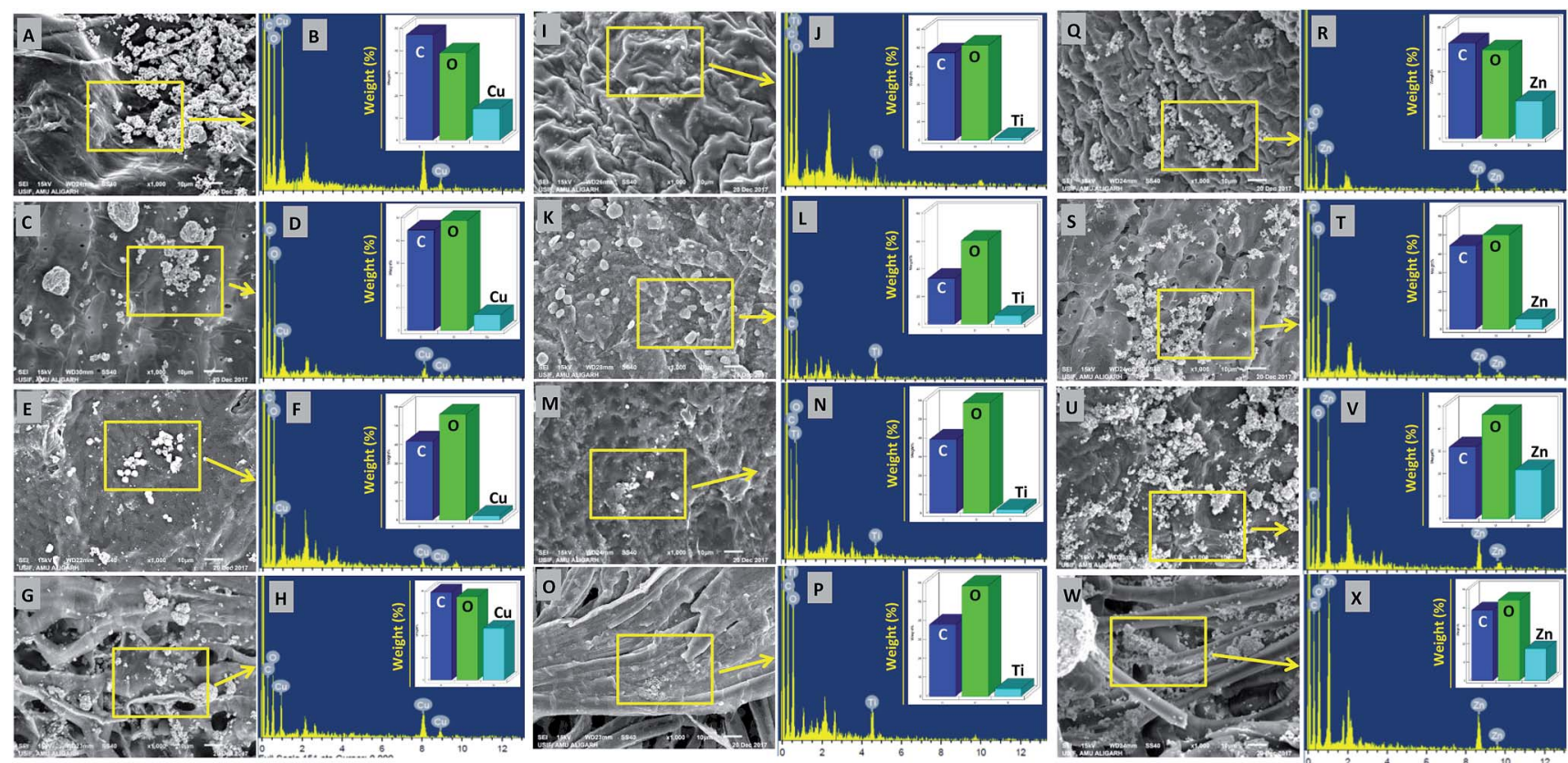

Fig. 4 SEM and EDX-based analysis of CuO-NPs adsorption and their detection by EDX on the surface of M. sativa (A and B), C. sativus (C and D), R. sativus ( $\mathrm{E}$ and $\mathrm{F}$ ), and S. lycopersicon ( $\mathrm{G}$ and $\mathrm{H}$ ) seeds after exposure to $\mathrm{CuO}-\mathrm{NPs}$ in water for $12 \mathrm{~h}$. Panels (I-P) show the adsorption of TiO ${ }_{2}^{-}$ NPs and their detection by EDX on the surface of M. sativa (I and J), C. sativus (K and L), R. sativus (M and N), and S. lycopersicon (O and P), while panels $(\mathrm{Q}-\mathrm{X})$ show the adsorption of $\mathrm{ZnO}-\mathrm{NPs}$ and their detection by EDX on the surface of $M$. sativa ( $\mathrm{Q}$ and $\mathrm{R}), \mathrm{C}$. sativus $(\mathrm{S}$ and $\mathrm{T}), R$. sativus $(\mathrm{U}$ and V), and S. lycopersicon (W and X). EDX spectra showed metal peaks and weight percentage of different elements. 

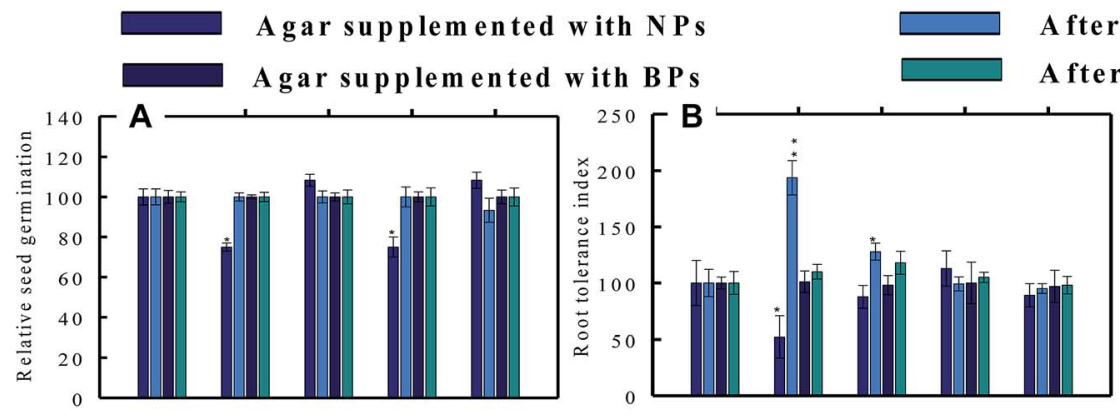

A fter soaking in NPs

After soaking in B Ps
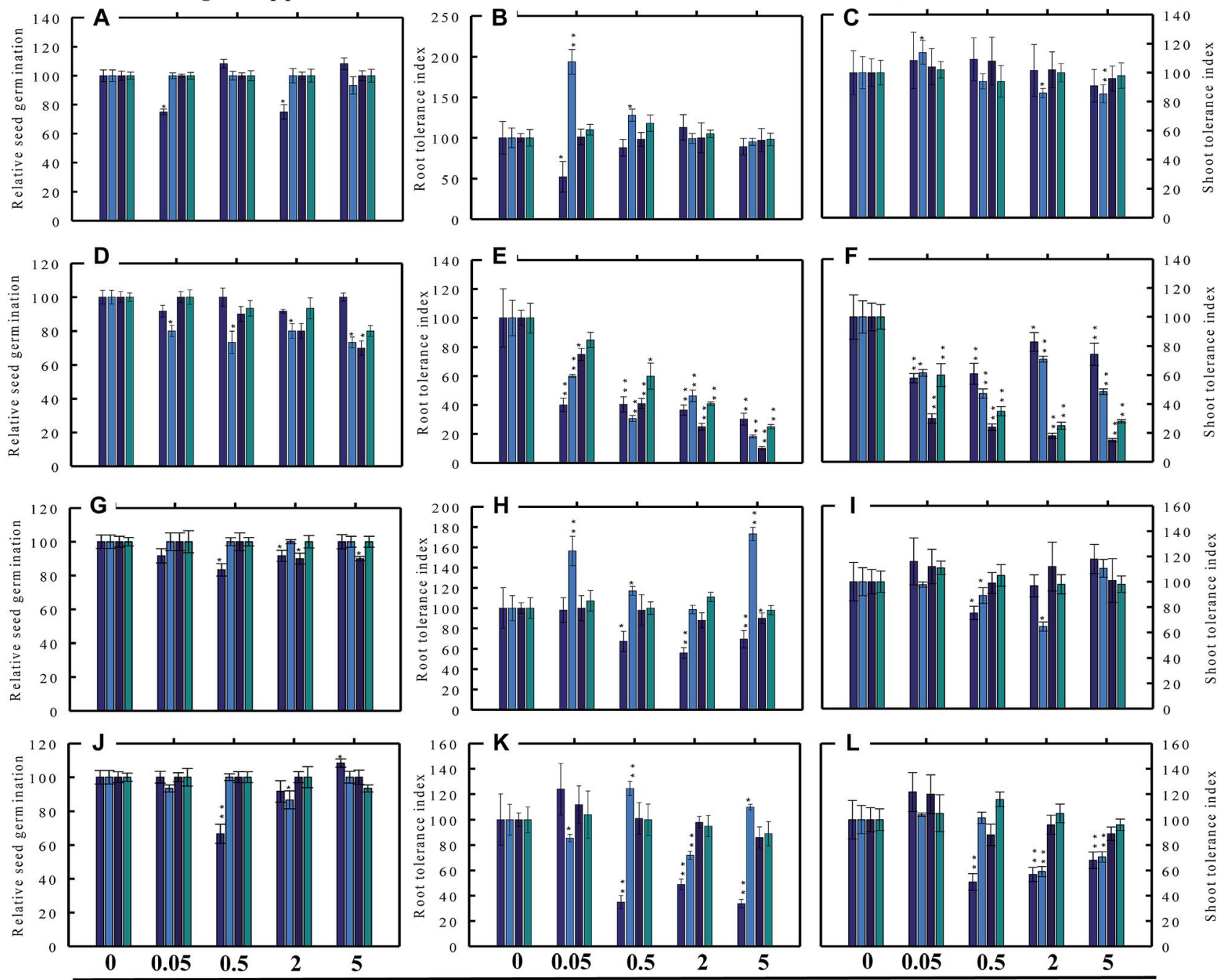

\section{Concentration $\left(\mathrm{mg} \mathrm{mL}^{-1}\right)$}

Fig. 5 Dose-response effect of NPs and $\mathrm{BPs}$ of $\mathrm{TiO}_{2}(\mathrm{~A}), \mathrm{ZnO}(\mathrm{B}), \mathrm{Al}_{2} \mathrm{O}_{3}(\mathrm{C})$, and $\mathrm{CuO}(\mathrm{D})$ before and after soaking (12 h) on relative seed germination ( $\mathrm{A}, \mathrm{D}, \mathrm{G}$ and $\mathrm{J})$, root tolerance index $(\mathrm{B}, \mathrm{E}, \mathrm{H}$ and $\mathrm{K})$, and shoot tolerance index $(\mathrm{C}, \mathrm{F}, \mathrm{I}$ and $\mathrm{L})$ of $R$. sativus. Values are given as mean \pm S.D. of three independent replicates at $* P \leq 0.01, * * P \leq 0.05$ vs. control.

the RSG maximally by $25 \%$ (Fig. 6a). On the contrary, $5 \mathrm{mg} \mathrm{ml}^{-1}$ $\mathrm{TiO}_{2}$-NPs reduced the RSG statistically $(P \leq 0.05)$ by $33 \%$ on supplemented agar medium (Fig. 6a). $\mathrm{TiO}_{2}$-BPs in contrast increased the RSG only at $2 \mathrm{mg} \mathrm{ml}^{-1}$ by $12 \%$ (Fig. 6a). Likewise, after soaking in ZnO-NPs ( 0.05 and $\left.0.5 \mathrm{mg} \mathrm{ml}^{-1}\right)$, the RSG was increased initially up to $12 \%$ but later it was reduced by $13 \%$ at $5 \mathrm{mg} \mathrm{ml}^{-1}$ (Fig. 6d). In contrast, ZnO-BPs reduced the RSG significantly $(P \leq 0.05)$ up to $25 \%$ on supplemented agar and up to $38 \%$ after soaking the seeds (Fig. 6d). None of the $\mathrm{Al}_{2} \mathrm{O}_{3}$-NPs or BPs concentrations altered the RSG of C. sativus except $5 \mathrm{mg}$ $\mathrm{ml}^{-1} \mathrm{Al}_{2} \mathrm{O}_{3}$-NPs, which reduced the RSG by $12 \%$ (Fig. $6 \mathrm{~g}$ ). Similarly, CuO-NPs did not show any negative impact on the RSG, while $5 \mathrm{mg} \mathrm{ml}^{-1} \mathrm{CuO}-\mathrm{BPs}$ reduced the RSG by $25 \%$ due to seed soaking (Fig. 6j).
3.3.3 Tomato (S. lycopersicon). $\mathrm{TiO}_{2}$-NPs in general were found inhibitory to tomato and reduced the RSG significantly $(P$ $\leq 0.05)$ up to $24 \%$ when soaked on supplemented agar medium and $27 \%$ after soaking in NPs solution (Fig. 7a). The germination of seeds incubated on agar supplemented with $\mathrm{TiO}_{2}$-BPs was also reduced up to $20 \%$, and hence both forms of $\mathrm{ZnO}$ were found significantly $(P \leq 0.05)$ inhibitory to the RSG of tomato. The ZnO-NPs and BPs reduced the RSG of tomato up to $39 \%$ and $60 \%(P \leq 0.05)$, respectively, on supplemented agar media (Fig. 7d). While, after soaking in ZnO-NPs and BPs, the RSG was limited up to $35 \%$ and $54 \%(P \leq 0.05)$, respectively (Fig. $7 \mathrm{~d}$ ). The inhibition of RSG by $\mathrm{Al}_{2} \mathrm{O}_{3}$-NPs was maximum at $5 \mathrm{mg} \mathrm{ml}^{-1}$ (39\%) when seeds were grown on NPs-supplemented agar medium (Fig. 7g). The reduced RSG of tomato also reduced 


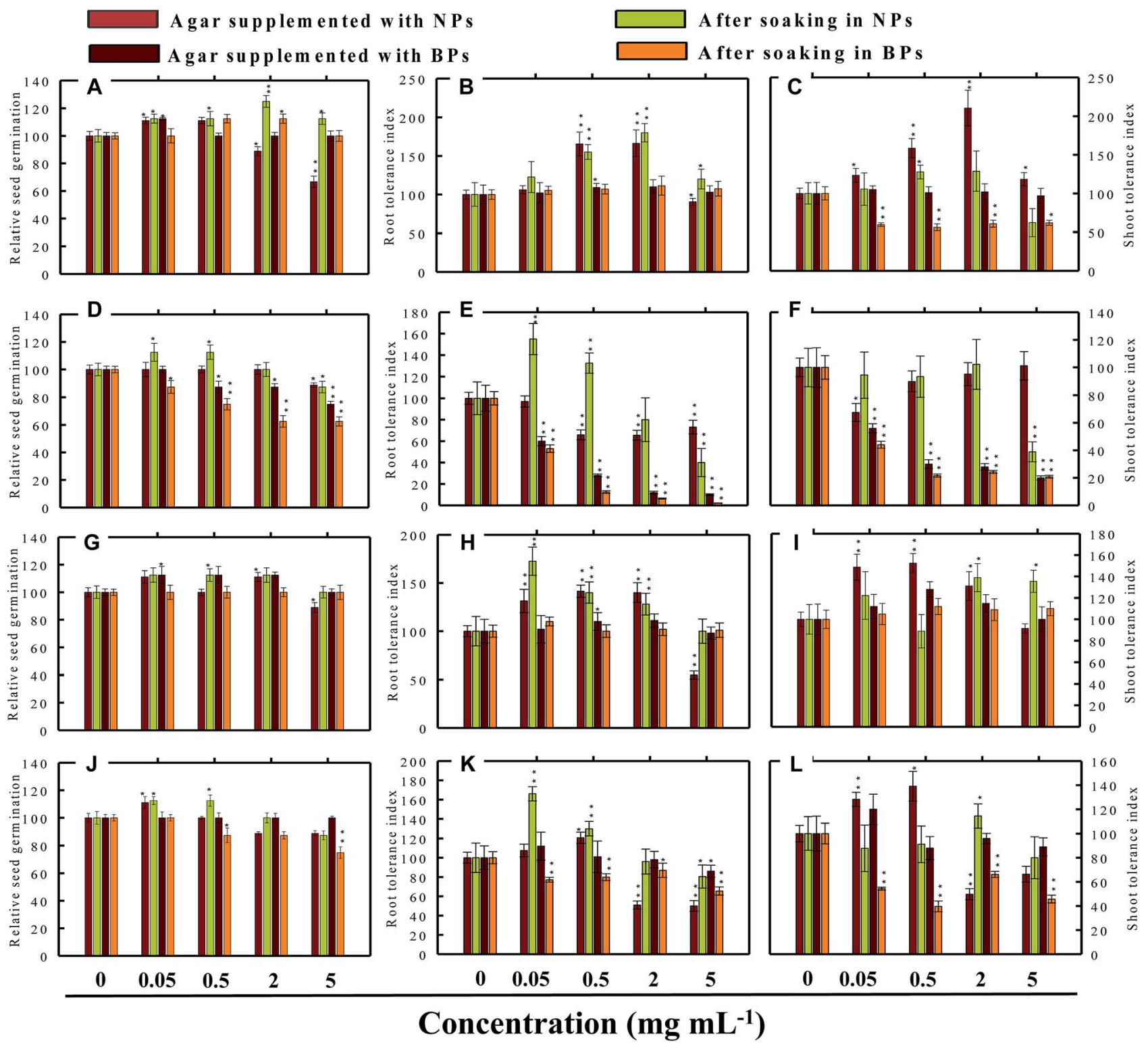

Fig. 6 Dose-response effect of NPs and $\mathrm{BPs}_{\mathrm{N}}$ of $\mathrm{TiO}_{2}(\mathrm{~A}), \mathrm{ZnO}(\mathrm{B}), \mathrm{Al}_{2} \mathrm{O}_{3}(\mathrm{C})$, and $\mathrm{CuO}(\mathrm{D})$ before and after soaking (12 h) on relative seed germination, ( $A, D, G$ and J), root tolerance index $(B, E, H$ and $K)$, and shoot tolerance index $(C, F, I$ and $L)$ of $C$. sativus. Values are given as mean \pm S.D. of three independent replicates at $* P \leq 0.01, * * P \leq 0.05$ vs. control.

substantially when plants were grown on agar medium treated with different concentrations of CuO-NPs and BPs (Fig. 7j).

3.3.4 Alfalfa (M. sativa). As for the RSG of $M$. sativa, only $\mathrm{TiO}_{2}$-NPs and BPs reduced germination by $16 \%$ and $14 \%$, respectively, at only $5 \mathrm{mg} \mathrm{ml}^{-1}$ (Fig. 8a). At 0.05 and $2 \mathrm{mg} \mathrm{ml}^{-1}$ concentration, the RSG of seeds soaked in $\mathrm{TiO}_{2}$-NPs increased up to 7\%. Rest of the concentrations of NPs and BPs were found to be passive on the RSG of M. sativa (Fig. 8a). Both ZnO-NPs and ZnO-BPs at $5 \mathrm{mg} \mathrm{ml}^{-1}$ had maximum inhibitory effect on the RSG of $M$. sativa (Fig. 8d). In contrast, $\mathrm{Al}_{2} \mathrm{O}_{3}$-NPs at $5 \mathrm{mg}$ $\mathrm{ml}^{-1}$, caused $15 \%$ increase in RSG (Fig. $8 \mathrm{~g}$ ) but other doses of $\mathrm{Al}_{2} \mathrm{O}_{3}$ were found to be ineffective. Contrarily, $\mathrm{Al}_{2} \mathrm{O}_{3}-\mathrm{NPs}$ and CuO-NPs declined the RSG up to $39 \%$ when raised on supplemented agar media and by $16 \%$ after dipping the seeds in CuONPs (Fig. 8j).
In support of our findings, alterations in seed germination of various plant species by metal and metal oxide NPs have been reported. ${ }^{4,18}$ For instance, nano forms of $\mathrm{NiO}, \mathrm{CuO}, \mathrm{TiO}_{2}, \mathrm{Co}_{3} \mathrm{O}_{4}$, and $\mathrm{Fe}_{2} \mathrm{O}_{3}$ have shown variable inhibitory effects on seed germination in radish, cucumber, and lettuce, which, however, differed with crop genotypes and seed size and followed the order: lettuce $>$ cucumber $>$ radish. ${ }^{19}$ In a similar study, LópezMoreno et al. reported a substantial reduction in the germination of tomato (30\%), cucumber $(20 \%)$, and maize $(30 \%)$ when exposed to cerium dioxide $\left(\mathrm{CeO}_{2}\right) \mathrm{NPs}$ at $2000 \mathrm{mg} \mathrm{l}^{-1}$ while germination of alfalfa plant remained unaffected..$^{20}$

In contrast, the application of $\mathrm{SiO}_{2} \mathrm{NPs}$ even at $8 \mathrm{~g} \mathrm{l}^{-1}$ dose rate did improve seed germination, seed vigor index, and the average germination time of tomato. ${ }^{21}$ Yet, some other studies have shown variable impact of $\mathrm{TiO}_{2}$-NPs on seed germination of maize, radish, 


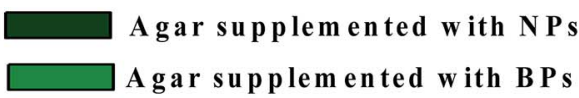

After soaking in N Ps

After soaking in $B$ Ps
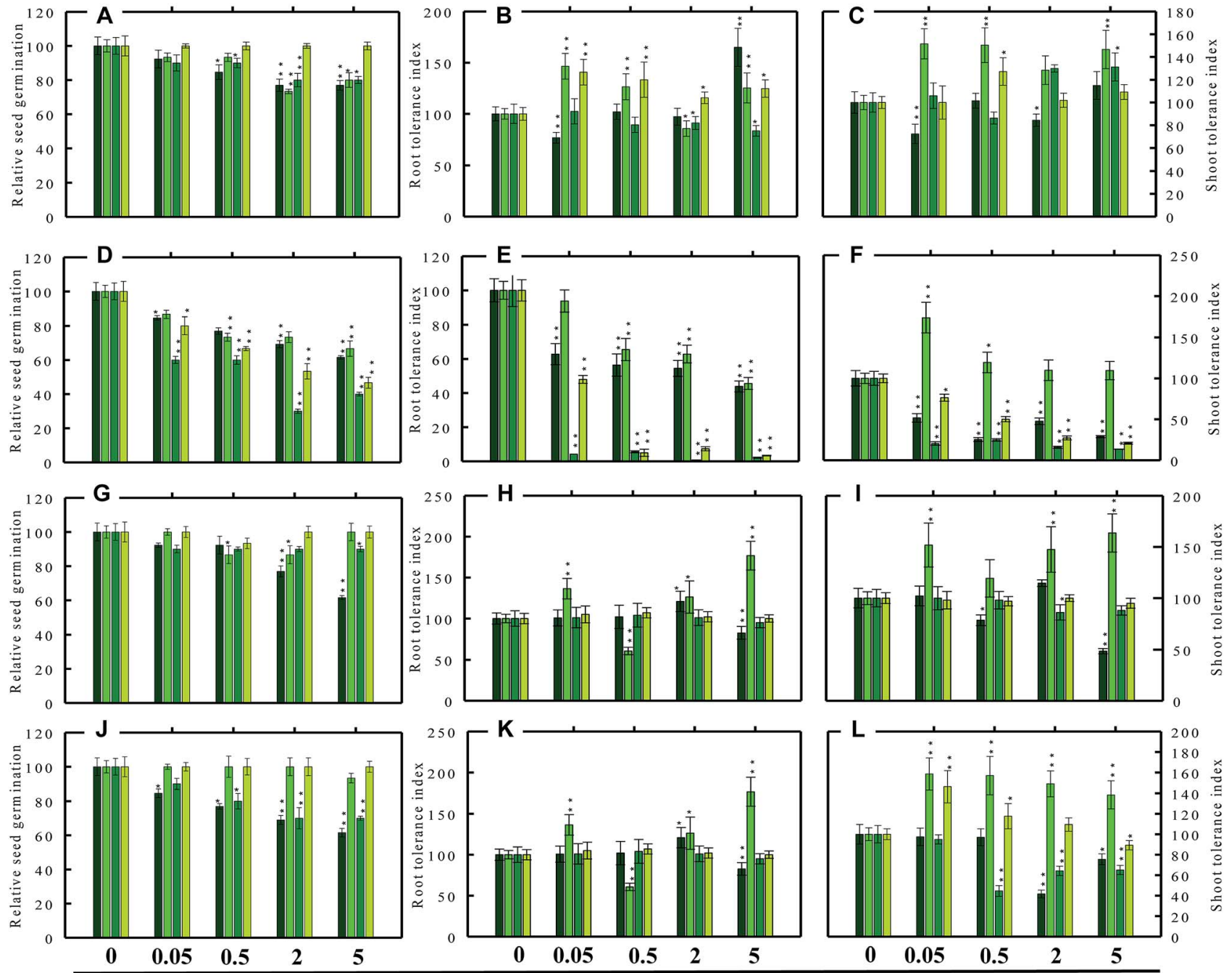

\section{Concentration $\left(\mathrm{mg} \mathrm{mL}^{-1}\right)$}

Fig. 7 Dose-response effect of NPs and $\mathrm{BPs}$ of $\mathrm{TiO}_{2}(\mathrm{~A}), \mathrm{ZnO}(\mathrm{B}), \mathrm{Al}_{2} \mathrm{O}_{3}(\mathrm{C})$, and $\mathrm{CuO}(\mathrm{D})$ before and after soaking (12 h) on relative seed germination, (A, D, G and j), root tolerance index (B, E, H and K), and shoot tolerance index $(C, F, I$ and $L)$ of $S$. lycopersicon. Values are given as mean \pm S.D. of three independent replicates at $* P \leq 0.01, * * P \leq 0.05 \mathrm{vs}$. control.

rapeseed, wheat, onion, tomato, fennel, and parsley. ${ }^{4,22,23}$ It has been reported that lower concentrations of NPs such as 10-40 ppm may enhance seed germination and seedling growth; however, concentrations $>50 \mathrm{ppm}$ have been found to exert a toxic impact on germination and seedling growth. ${ }^{\mathbf{1 8 , 2 4}}$ Despite increase or decrease, it has been reported that aqueous $\mathrm{TiO}_{2}$-NP suspensions (14-25 $\mathrm{nm}$ ) did not affect germination in rapeseed and wheat up to 100 ppm concentration. ${ }^{25}$ Recently, the treatment of rice seeds with 100-1000 ppm of $\mathrm{TiO}_{2}$ - and $\mathrm{ZnO}-\mathrm{NPs}$ was found to be passive for seed germination even after soaking the seeds for three days. ${ }^{26}$ In another study, $100 \%$ seed germination was recorded upon exposure of tomato and onion seeds to $100 \mathrm{mg} \mathrm{ml}^{-1} \mathrm{TiO}_{2}$-NPs, while radish seeds were able to germinate by $100 \%$ at $400 \mathrm{mg} \mathrm{ml}^{-1} .^{27}$ More recently, ZnO-NPs were found inert on seed germination of Zea mays and C. sativus. ${ }^{28}$
Despite conflicting reports on the effect of NPs on the germination efficiency of many plants, the current findings clearly suggest that lower concentrations of NPs may serve as seed-priming agents, but at higher concentrations the same NPs have deleterious impact on RSG. Among metal NPs, those prepared from $\mathrm{Zn}$ were found more inhibitory to all vegetable species.

\subsection{Root and shoot development of vegetables under stress}

The impact of NPs and BPs on root (RTI) and shoot growth (STI) of radish, cucumber, tomato and alfalfa varied with dose rates of both NPs and BPs (Fig. 5-8). The findings observed in this study are explained in the following sections.

3.4.1 Effect of $\mathrm{TiO}_{2}$-NPs and BPs. The $\mathrm{TiO}_{2}$-NPs and BPs as a whole did not reduce the growth of the four vegetables 
significantly. Instead, some $\mathrm{TiO}_{2}$-NPs and $\mathrm{BPs}$ facilitated the growth of both root and shoot until certain concentrations. For instance, $0.05 \mathrm{mg} \mathrm{ml}^{-1} \mathrm{TiO}_{2}$-NPs maximally increased the RTI of $R$. sativus by $93 \%$ after soaking (Fig. 5b), whereas, the STI was enhanced by $13 \%$ (Fig. 5c). Similarly, $\mathrm{TiO}_{2}-\mathrm{NPs}$ produced a dosedependent increase in the RTI of C. sativus up to $66 \%$ (on supplemented agar) and $80 \%$ (after soaking) (Fig. 6b). The STI of $C$. sativus was augmented up to $110 \%$ (on supplemented agar) and $28 \%$ (after soaking) (Fig. 6c). After soaking in $\mathrm{TiO}_{2}$-BPs, the STI of C. sativus, in contrast, was inhibited up to $39 \%$ but remained constant (44-39\%) up to $5 \mathrm{mg} \mathrm{ml}^{-1}$ (Fig. 6c). Similar increase in RTI and STI was observed for S. lycopersicon (Fig. 7b and c) and $M$. sativa (Fig. $8 \mathrm{~b}$ and c). Root enhancement by $\mathrm{TiO}_{2}$ NPs in $S$. lycopersicon was up to $65 \%$ (on supplemented agar) and $25 \%$ (after soaking) (Fig. 7b), while, the maximum increment in shoot length was $14 \%$ (on supplemented agar) and 50\% (after soaking) (Fig. 7c). Interestingly, after soaking in $\mathrm{TiO}_{2}$-BPs, a maximum increase of $24 \%$ in root length was also noticed (Fig. 7b). After soaking in $0.05 \mathrm{mg} \mathrm{ml}^{-1}$ of $\mathrm{TiO}_{2}$-NPs, the RTI of $M$. sativa was enhanced significantly $(P \leq 0.05)$ by $74 \%$, which decreased thereafter in a concentration-dependent fashion (Fig. 8b). Except for $44 \%(P \leq 0.05)$ reduction in root length on supplemented agar, no significant effects on root and shoot elongation was observed for other concentrations of $\mathrm{TiO}_{2}$-BPs.

3.4.2 Effect of ZnO-NPs and BPs. In general, the ZnO-NPs and BPs displayed severe toxic impact on root and shoot elongation of all test vegetables, which however, differed with the concentration of each NP and BP. The maximum inhibition of the RTI of $R$. sativus was 75\% (ZnO-NPs + agar), 82\% (after soaking in ZnO-NPs), 90\% (ZnO-BPs + agar), and 75\% (after soaking in ZnO-BPs) (Fig. 5e). Likewise, maximum reduction in STI was found as 26\% (ZnO-NPs + agar), 52\% (after soaking in ZnO-NPs), 85\% (ZnO-BPs + agar), and 72\% (after soaking in ZnO-BPs) (Fig. 5f). The 50\% inhibitory concentration $\left(\mathrm{IC}_{50}\right)$ was defined in the current study as the concentration of NPs or BPs at which the root or shoot length shows a $50 \%$ decrease $v s$. the untreated control $(100 \%)$. The $\mathrm{IC}_{50}$ of $\mathrm{ZnO}-\mathrm{NPs}$ for $R$. sativus roots was found to be 0.05 (ZnO-NPs + agar) and $0.5 \mathrm{mg} \mathrm{ml}^{-1}$ (after soaking in ZnO-NPs). The BP of $\mathrm{ZnO}$ was also detrimental to the roots and shoots of $R$. sativus. The $\mathrm{IC}_{50}$ on supplemented agar treatments was $0.5 \mathrm{mg} \mathrm{ml}^{-1}$ for roots and $0.05 \mathrm{mg} \mathrm{ml}^{-1}$ for shoots, whereas, it was $2 \mathrm{mg} \mathrm{ml}^{-1}$ for roots and $0.5 \mathrm{mg} \mathrm{ml}^{-1}$ for shoots emerged from seeds after soaking in ZnO-BPs. Moreover, a $90 \%$ inhibitory concentration $\left(\mathrm{IC}_{90}\right)$ was also observed for roots of $R$. sativus grown on ZnO-BPs-supplemented agar. For shoots of $C$. sativus, the $\mathrm{IC}_{50}$ for ZnO-NPs was found to be $5 \mathrm{mg}$ $\mathrm{ml}^{-1}$ after soaking, while for ZnO-BPs, it was $0.5 \mathrm{mg} \mathrm{ml}^{-1}$ for both roots and shoots developed on supplemented agar and 0.5 and $0.05 \mathrm{mg} \mathrm{ml} \mathrm{m}^{-1}$ for roots and shoots after soaking. After a significant increase in root length $(55 \%)$ at $0.05 \mathrm{mg} \mathrm{ml}^{-1}$ of ZnO-NPs (after soaking), it decreased in a dose-dependent manner and was found to be maximum (60\%) at $5 \mathrm{mg} \mathrm{ml} \mathrm{m}^{-1}$ (Fig. 6e). Similarly, BPs also decreased root and shoot elongation in a dose-dependent manner with $\mathrm{IC}_{90}$ of $5 \mathrm{mg} \mathrm{ml}^{-1}$ (on supplemented agar) and $2 \mathrm{mg} \mathrm{ml}^{-1}$ (after soaking) (Fig. 6e). The root and shoot length of $S$. lycopersicon also decreased significantly $(P \leq 0.05)$ with increase in concentration of ZnO-NPs and
BPs. $\mathrm{IC}_{50}$ for different treatments followed the order: $5 \mathrm{mg} \mathrm{ZnO}-$

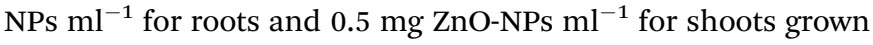
on supplemented agar, $5 \mathrm{mg} \mathrm{ZnO}-\mathrm{NPs} \mathrm{ml}^{-1}$ for roots grown

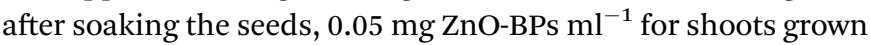
on supplemented agar, and $0.05 \mathrm{mg} \mathrm{ZnO}-\mathrm{BPs} \mathrm{ml} \mathrm{m}^{-1}$ for roots and $2 \mathrm{mg} \mathrm{ml}{ }^{-1}$ for shoots grown after soaking treatment. The $\mathrm{IC}_{90}$ calculated for ZnO-BPs was $0.05 \mathrm{mg} \mathrm{ml}^{-1}$ for roots on supplemented agar and $0.5 \mathrm{mg} \mathrm{ml}^{-1}$ for shoots after soaking. Beside the growth-inhibitory effects of ZnO-NPs on S. lycopersicon, a significant enhancement in shoot height was also observed for all concentrations of ZnO-NPs due to soaking (Fig. 7f). Among all plants, shoot growth of $M$. sativa was least affected by $\mathrm{ZnO}-$ $\mathrm{NP}$ and BP treatments (Fig. 8f); whereas, root elongation decreased with increase in concentration (Fig. 8e). The lowest concentration of $\mathrm{ZnO}-\mathrm{NPs}\left(0.05 \mathrm{mg} \mathrm{ml}^{-1}\right)$ showed $28 \%$ increase in root elongation (Fig. 8e). $\mathrm{IC}_{50}$ for $M$. sativa roots grown before and after soaking in $\mathrm{ZnO}-\mathrm{NPs}$ was found to be 5 and $0.5 \mathrm{mg}$ $\mathrm{ml}^{-1}$, whereas, for $\mathrm{ZnO}-\mathrm{BPs}$, it was $5 \mathrm{mg} \mathrm{ml} \mathrm{ml}^{-1}$ for both treatments.

3.4.3 Effect of $\mathrm{Al}_{2} \mathrm{O}_{3}$-NPs and BPs. The $\mathrm{Al}_{2} \mathrm{O}_{3}$-NPs decreased the RTI of $R$. sativus up to $45 \%$ in a concentration-dependent manner on supplemented agar media, whereas, $5 \mathrm{mg} \mathrm{ml} \mathrm{ml}^{-1}$ showed $73 \%$ increase after soaking (Fig. 5 h). For C. sativus, only $5 \mathrm{mg} \mathrm{ml}^{-1}$ of $\mathrm{Al}_{2} \mathrm{O}_{3}$-NPs decreased RTI and STI by $46 \%$ while all other concentrations enhanced RTI and STI from 10\% to $72 \%$ (Fig. 6h and i). Likewise, only $5 \mathrm{mg} \mathrm{Al}_{2} \mathrm{O}_{3}-\mathrm{NPs} \mathrm{ml}^{-1}$ decreased RTI and STI of S. lycopersicon by $18 \%$ and $52 \%$, respectively, on supplemented agar (Fig. 7h and i). The RTI was promoted from $20 \%-76 \%$ on exposure to $\mathrm{Al}_{2} \mathrm{O}_{3}$-NPs and $\mathrm{BPs}$ at various concentrations (Fig. 7h), while enhancement in STI varied between $14 \%$ and $63 \%$ (Fig. 7i). The $\mathrm{Al}_{2} \mathrm{O}_{3}$-NPs and BPs, however, showed poor inhibitory effect on $M$. sativa (Fig. $8 \mathrm{~h}$ and i). As an example, $\mathrm{Al}_{2} \mathrm{O}_{3}$-NPs at $5 \mathrm{mg} \mathrm{ml}^{-1}$, increased the RTI by $44 \%$ (Fig. 8h), while STI was found highest (37\%) at $2 \mathrm{mg} \mathrm{Al}_{2} \mathrm{O}_{3}$ NPs $\mathrm{ml}^{-1}$ (Fig. 8i).

3.4.4 Effect of CuO-NPs and BPs. A significant negative influence on RTI and STI of plants grown under CuO-NPs and BPs was observed. The CuO-NPs significantly $(P \leq 0.05)$ decreased RTI and STI of $R$. sativus from 15\%-67\% (Fig. 5k and 1). Similar toxic effects were also observed for cucumber (Fig. 6k and 1), tomato (Fig. 7k and 1) and alfalfa (Fig. 8k and l). Besides exhibiting an inhibitory impact, some concentrations of $\mathrm{CuO}$ NPs and BPs also showed growth-promoting effects, and, hence, enhanced the length of roots (RTI) and shoots (STI) of vegetables.

In our study, heavy MONPs exhibited dual characteristics, which has been reported only in few studies. In literature, the negative effects of metal-based NPs like $\mathrm{ZnO}, \mathrm{Al}_{2} \mathrm{O}_{3}, \mathrm{CuO}$, and $\mathrm{TiO}_{2}$ on shoot/root elongation and growth have been reported in various cereals (wheat, rice, maize, and barley) and certain vegetables (for example, tomato). The increased toxicity of NPs has been suggested to be due to the interaction that occurs between the NPs and plant exudates and the consequent release of metal ions from the NPs in growth media. ${ }^{29,30}$ The phytotoxic effect of $\mathrm{Al}_{2} \mathrm{O}_{3}$-NPs is largely considered to be inhibitory or neutral on plant growth. ${ }^{31,32}$ Therefore, their positive effect on root and shoot elongation is unexpected. 


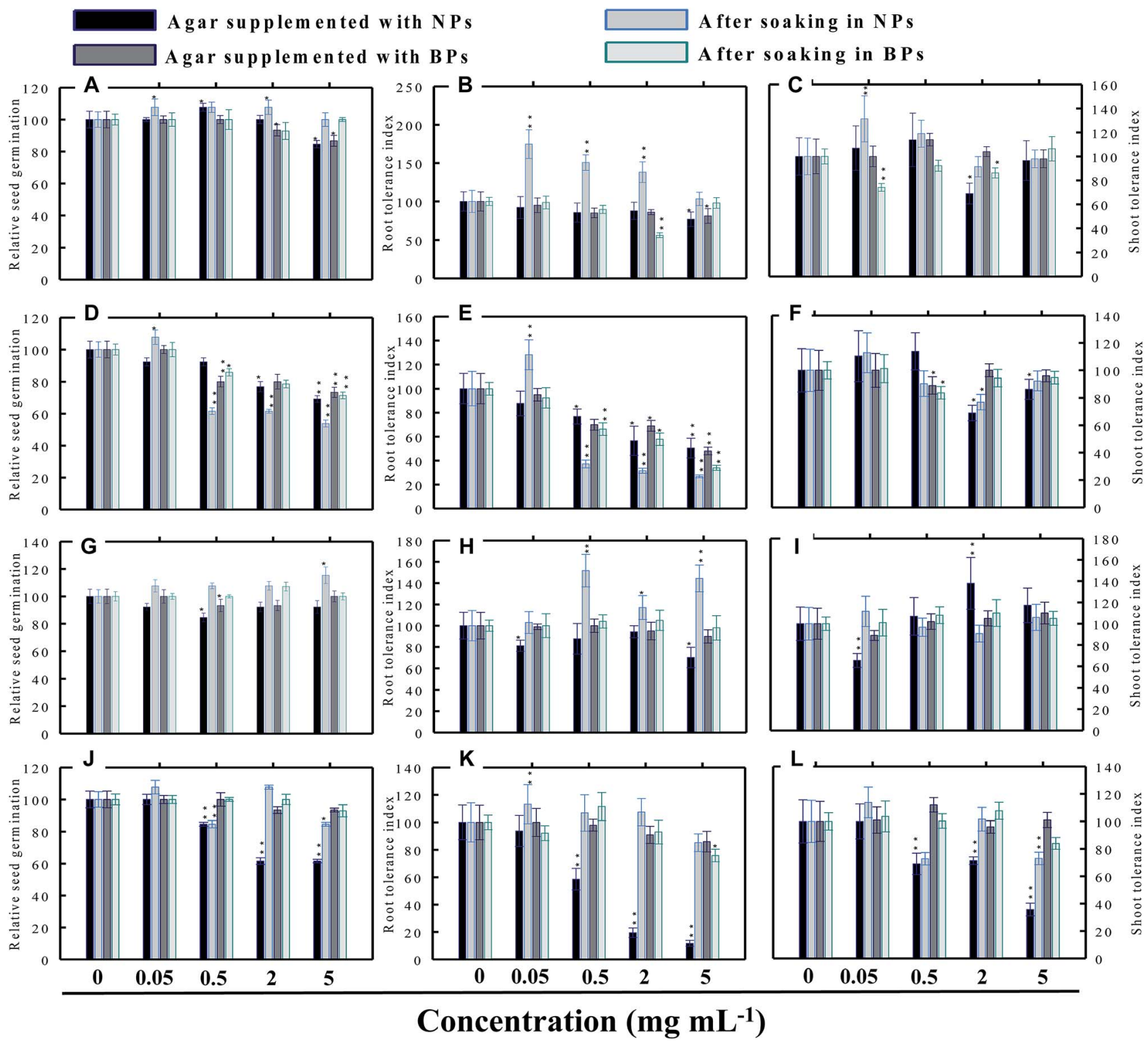

Fig. 8 Dose-response effect of NPs and $\mathrm{BPs}_{\text {of }} \mathrm{TiO}_{2}(\mathrm{~A}), \mathrm{ZnO}(\mathrm{B}), \mathrm{Al}_{2} \mathrm{O}_{3}(\mathrm{C})$, and $\mathrm{CuO}(\mathrm{D})$ before and after soaking (12 h) on relative seed germination, ( $A, D, G$ and $J)$, root tolerance index (B, E, $H$ and $K)$, and shoot tolerance index $(C, F, I$ and $L)$ of $M$. sativa. Values are given as mean \pm S.D. of three independent replicates at $* P \leq 0.01$, **P $\leq 0.05$ vs. control.

Even though the factors affecting the enhancement in root elongation following BP exposure are unclear, it might be presumed that since the agar matrix is nonporous the BPs are possibly trapped inside the polymeric network of polysaccharides (agar), and, therefore, the entry of BPs within the tissues of roots/shoots is restricted. On the other hand, nano forms of metals, for example $\mathrm{TiO}_{2}$-NPs and nanowires, have shown to significantly enhance root elongation and seed germination of wheat and lettuce as compared to bulk materials. ${ }^{22,33}$ This type of growth promotion also depends on - (i) the concentration and duration of NP exposure (ii) growth environment and (iii) plant species. ${ }^{4,34}$ In line with our study, lower range of $\sim 20 \mathrm{~nm}$-sized $\mathrm{TiO}_{2}$-NPs $(10-100 \mathrm{ppm})$ significantly increased root and shoot fresh biomass, whereas concentration
$>100$ ppm was detrimental. ${ }^{33}$ Surprisingly, in another work, even 1000-5000 ppm of $\mathrm{TiO}_{2}$-NPs did not significantly change the biomass of tomato. ${ }^{35}$ Fragmentation of cellular DNA was also observed due to the toxicity of ZnO-NPs in onion. ${ }^{36}$ The exposure of wheat to CuO-NPs showed $5 \%$ and $13 \%$ decrease in root and shoot lengths, respectively, and exhibited necrosis in roots which as a result were thinner and more brittle compared to the control. ${ }^{37}$ Among the bulk materials tested, ZnO-BPs were also found toxic to seedlings specifically of $C$. sativus and $S$. lycopersicon. This could be due to following reasons - (i) chemical: release of $\mathrm{Zn}^{2+}$ ions from ZnO-NPs in growth medium followed by their uptake by seeds and seedlings above threshold level and (ii) physical intervention of ZnO-BPs with plant roots which might have blocked the water transport. NPs as a whole, 


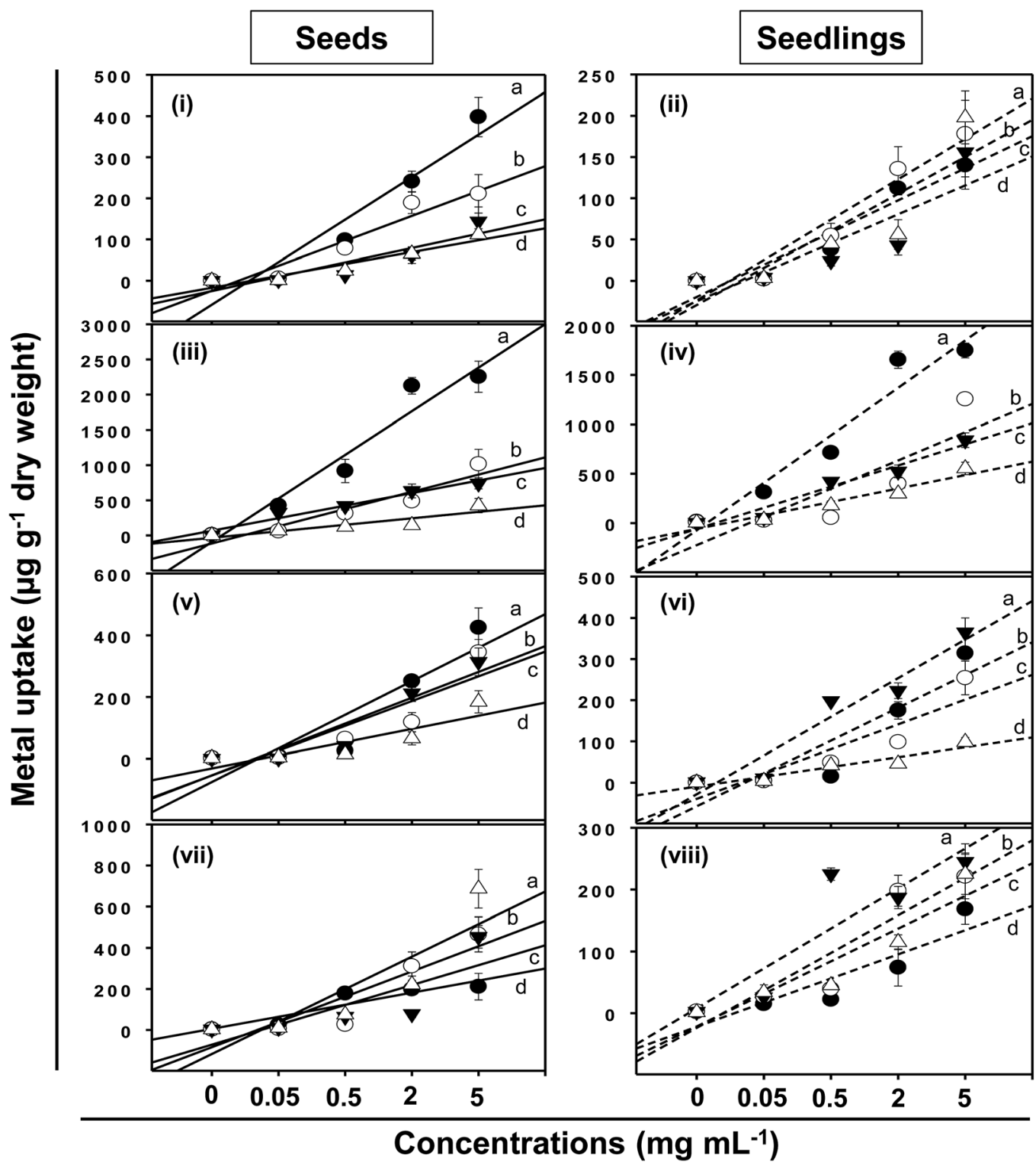
(a) R. sativus
(b) $\bigcirc$ c. sativus
(c) $\nabla$ s. lycopersicon
(d) $\triangle$ M. sativa

Fig. 9 Linear line and scatter plots showing concentration-dependent uptake of heavy MONPs in seeds and seedlings exposed to $0.05-5 \mathrm{mg}$ $\mathrm{ml}^{-1} \mathrm{NPs}$ of $\mathrm{TiO}_{2}$ (i and ii), $\mathrm{ZnO}$ (iii and iv), $\mathrm{Al}_{2} \mathrm{O}_{3}$ ( $\mathrm{v}$ and vi), and $\mathrm{CuO}$ (vii and viii). Letters a, b, c, and d represent $R$. sativus, C. sativus, S. lycopersicon, and M. sativa, respectively. Error bars stand for experiments performed in triplicates $(n=3)$.

may interfere with plant metabolism in several ways, such as by providing micronutrients, down and up regulation of genes, and interfering with oxidative processes, which result in oxidative burst. ${ }^{30,38,39}$ The entered nanoparticles can also interfere with the electron transport chain of mitochondria and chloroplast. $^{1}$

\subsection{NPs uptake by seeds and seedlings}

Following adsorption onto seeds and plant surfaces, $\mathrm{TiO}_{2}-\mathrm{NPs}$, $\mathrm{ZnO}-\mathrm{NPs}, \mathrm{Al}_{2} \mathrm{O}_{3}$-NPs, and CuO-NPs entered inside plant tissues and growing seedlings of test crops (Fig. 9). The concentration of MONPs, however, differed in a dose-dependent manner and varied greatly between seeds and seedlings of each plant. For example, the content of Ti accumulated within the seeds of $R$. sativus growing at 0.05-5 $\mathrm{mg} \mathrm{Ti} \mathrm{ml}^{-1}$ ranged between 4 and 398

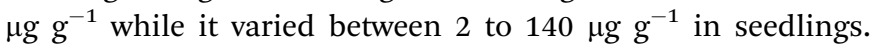
Likewise, the concentration of $\mathrm{Ti}$ in seeds/seedlings of $C$. sativus, S. lycopersicon and $M$. sativa was recorded as $\left(\mu \mathrm{g} \mathrm{g}^{-1}\right): 211 /$ 178, 144/156, and 112/198, respectively (Fig. 9i and ii). Similarly, the ZnO-NPs were found maximum in seeds/seedlings of $R$. sativus among all test plants $\left(2254 / 1748 \mu \mathrm{g} \mathrm{g}^{-1}\right)$ which was followed by C. sativus (1015/1254 $\left.\mu \mathrm{g} \mathrm{g}^{-1}\right)$, S. lycopersicon $(741 / 850$ $\left.\mu \mathrm{g} \mathrm{g}^{-1}\right)$ and M. sativa (425/554 $\mu \mathrm{g} \mathrm{g}^{-1}$ ) (Fig. 9iii and iv). The uptake of $\mathrm{Al}_{2} \mathrm{O}_{3}$-NPs (Fig. 9v and vi) and CuO-NPs (Fig. 9vii and viii) in seeds/seedlings of $R$. sativus, C. sativus, S. lycopersicon, and $M$. sativa followed a trend similar to those recorded for other MONPs. Summarily, the uptake pattern of heavy MONPs in seeds (A) and seedlings (B) of different crops followed the order: 


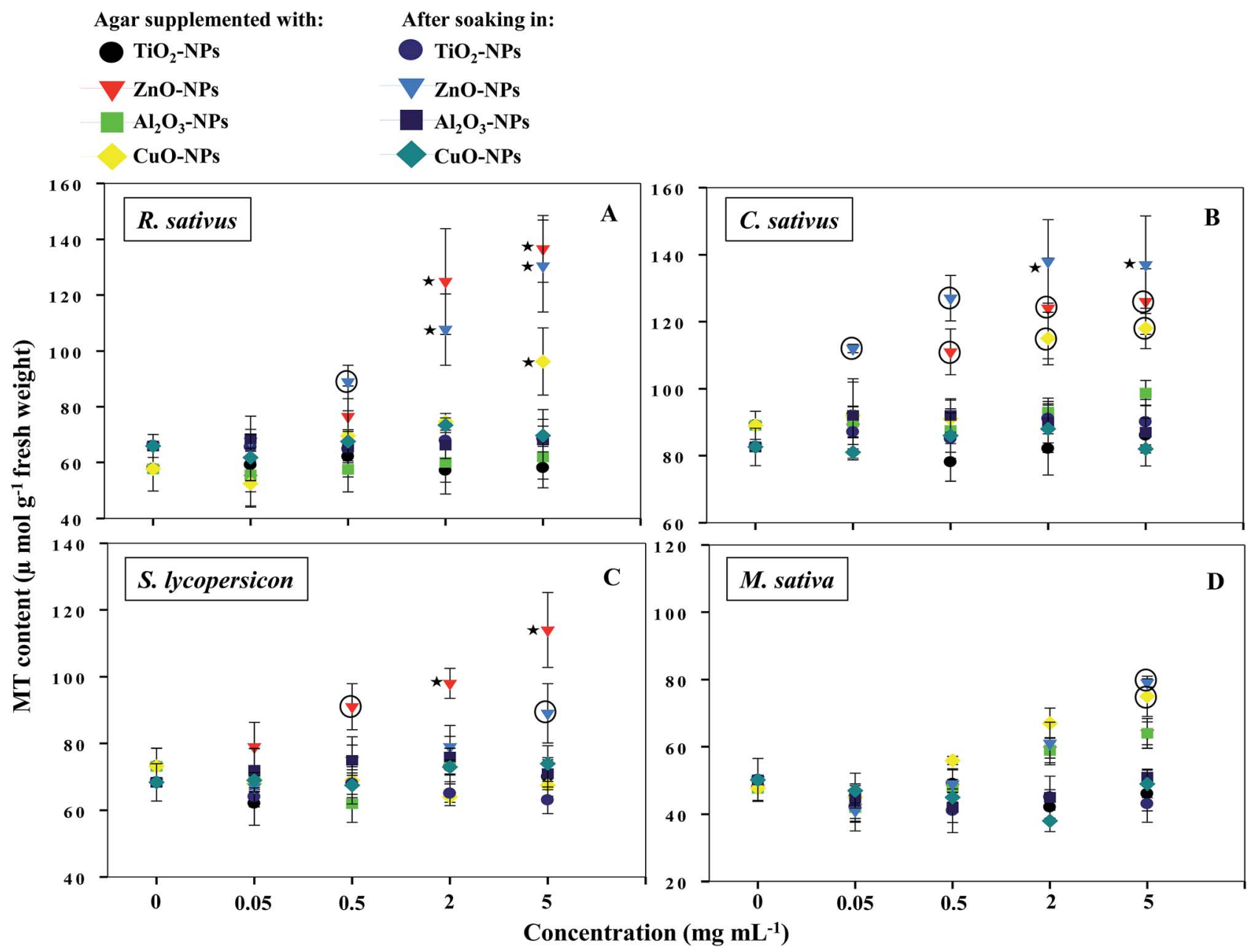

Fig. 10 Dot plot of spectrophotometric detection of $\mathrm{MTs}_{\mathrm{in}} \mathrm{TiO}_{2^{-}}, \mathrm{ZnO}-, \mathrm{Al}_{2} \mathrm{O}_{3}{ }^{-}$, and $\mathrm{CuO}-\mathrm{NP}$-treated R. sativus (A), C. sativus (B), S. lycopersicon (C), and M. sativa (D). Values are given as mean \pm S.D. of experiments performed in triplicates $(n=3)$ with 10 seeds per replicate. Dots encircled and marked with star represent $P \leq 0.01$ and $P \leq 0.05$ vs. control, respectively.

A: (i) $\mathrm{TiO}_{2}-\mathrm{NPs}-R$. sativus $>$ C. sativus $>$ S. lycopersicon $>M$. sativa; (ii) ZnO-NPs $-R$. sativus $>$ C. sativus $>$ S. lycopersicon $>M$. sativa; (iii) $\mathrm{Al}_{2} \mathrm{O}_{3}-\mathrm{NPs}-R$. sativus $>C$. sativus $>$ S. lycopersicon $>$ $M$. sativa; (iv) CuO-NPs $-M$. sativa $>C$. sativus $>$ S. lycopersicon $>$ R. sativus.

B: (i) $\mathrm{TiO}_{2}-\mathrm{NPs}-M$. sativa $>$ C. sativus $>$ S. lycopersicon $>R$. sativus; (ii) ZnO-NPs $-R$. sativus $>C$. sativus $>$ S. lycopersicon $>M$. sativa; (iii) $\mathrm{Al}_{2} \mathrm{O}_{3}-\mathrm{NPs}-S$. lycopersicon $>R$. sativus $>C$. sativus $>$ $M$. sativa; (iv) CuO-NPs $-S$. lycopersicon $>M$. sativa $>C$. sativus $>$ R. sativus.

An increase from 2 to $5 \mathrm{mg} \mathrm{ml}^{-1}$ of MONPs did not show any significant enhancement in metal uptake by seeds except for the ZnO-NP uptake by M. sativa and C. sativus. Similar observations were made in case of metal uptake in seedlings again with the exception of ZnO-NP uptake in C. sativus, S. lycopersicon, and $M$. sativa. This variation in MONP uptake could possibly be due to the differences in the aggregate-forming ability of NPs. ${ }^{40}$ However, despite variations, similar accumulation of MONPs has been reported in many plants. In a study, $\mathrm{Al}_{2} \mathrm{O}_{3}$-NPs at $1000 \mathrm{mg} \mathrm{l}^{-1}$ resulted in $350.5 \mu \mathrm{g} \mathrm{g}^{-1}$ accumulation of $\mathrm{Al}$ in plants, which did not cause root-growth inhibition. ${ }^{13}$ This could be explained to be due to the compartmentalization of inert MONPs in various plant cell organelles. ${ }^{\mathbf{4 1 , 4 2}}$ Moreover, a limited uptake of $\mathrm{TiO}_{2}$-NPs by lettuce occurred due to the aggregation of NPs to much larger sizes after being mixed with the cultivation media. ${ }^{33}$ It has been suggested that the higher content of metal NPs in seedlings is a result of extensive attachment of particles on plant surfaces. ${ }^{13}$ Suriyaprabha et al. reported the bioaccumulation of transition metal oxide $\left(\mathrm{Fe}_{2} \mathrm{O}_{3}, \mathrm{CuO}\right.$ and $\left.\mathrm{ZnO}\right)$ NPs and their influence on Vigna unguiculata seeds. ${ }^{43}$ Apart from these, MONPs, for example CuO-NPs, are reported to induce DNA damage besides altering the structure of plant roots. ${ }^{\mathbf{4 4 , 4 5}}$ The accumulation of MONPs within plant tissues, however, poses a serious and unexpected threat to human health which requires urgent attention.

\subsection{Production of metallothioneins}

NPs that once enter the plant tissues, are likely to be transformed, which can be mediated by cellular metabolic processes. ${ }^{1}$ During such processes, heavy metal ions are released from NPs, which in turn induce the generation of ROS and cause membrane lipid peroxidation., ${ }^{5,14}$ In contrast, plants 


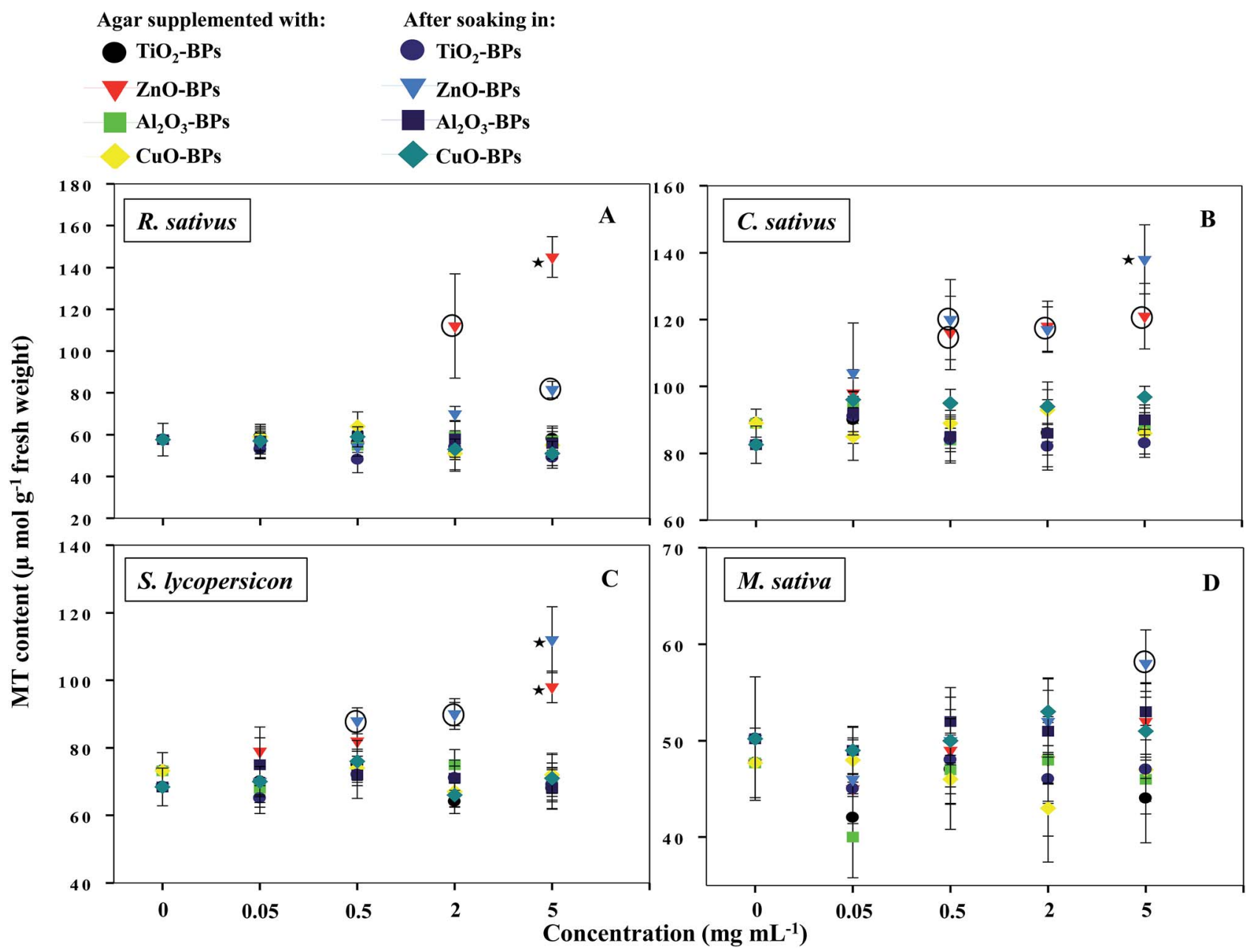

Fig. 11 Dot plot of spectrophotometric detection of $\mathrm{MTS}_{\mathrm{in}} \mathrm{TiO}_{2^{-}}, \mathrm{ZnO}-, \mathrm{Al}_{2} \mathrm{O}_{3^{-}}$, and $\mathrm{CuO}-\mathrm{BP}$-treated R. sativus (A), C. sativus (B), S. lycopersicon (C), and M. sativa (D). Values are given as mean \pm S.D. of experiments performed in triplicates $(n=3)$ with 10 seeds per replicate. Dots encircled and marked with star represent $P \leq 0.01$ and $P \leq 0.05$ vs. control, respectively.

have evolved certain mechanisms like the synthesis of metallothioneins (MTs) to hammer out metal toxicity; the binding affinity of MTs, however, varies with metal species. ${ }^{46}$ To the best of our information, the generation of MTs has yet not been reported as a phytotoxicity endpoint of NPs. Hence, the release of MTs by plants after soaking seeds in various concentrations of MONPs and BPs and growing them on supplemented semi-solid agar plates was detected and measured (Fig. 10a-d and Fig. 11ad). Roots of untreated $R$. sativus, C. sativus, S. lycopersicon, and

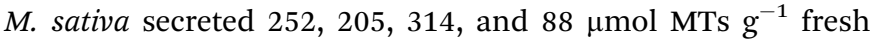
weight (FW). Among the species of metals used in this study, only bulk and NPs of $\mathrm{ZnO}$ and $\mathrm{CuO}$ were found stimulatory for MTs while MTs produced under exposure to $\mathrm{TiO}_{2}{ }^{-}$and $\mathrm{Al}_{2} \mathrm{O}_{3^{-}}$ NPs and BPs were statistically insignificant. MT production under ZnO-NPs and BPs followed a dose-dependent increase (Fig. 10 and 11). At $5 \mathrm{mg} \mathrm{ml}^{-1}$ ZnO-NPs, MT production in $R$. sativus was significantly high $\left(136 \mu \mathrm{mol} \mathrm{MTs}^{-1} \mathrm{FW}\right)$ as compared to the negative control $\left(57 \mu \mathrm{mol} \mathrm{MTs} \mathrm{g}^{-1} \mathrm{FW}\right)$ when grown on supplemented agar (Fig. 10a). Similarly, soaking of seeds in $0.5,2$, and $5 \mathrm{mg} \mathrm{ml}^{-1}$ ZnO-NPs resulted in the significant production of MTs: 85, 110 and $140 \mu \mathrm{mol} \mathrm{MTs} \mathrm{g}^{-1} \mathrm{FW}$, respectively. Of the different CuO-NP concentrations, only $5 \mathrm{mg}$ $\mathrm{ml}^{-1}$ of CuO-NPs exhibited significant $(P \leq 0.05)$ production of MTs $\left(96.2 \mu \mathrm{mol}\right.$ MTs $\mathrm{g}^{-1} \mathrm{FW}$ ) (Fig. 10a). C. sativus on agar supplemented with ZnO-NPs and after soaking in ZnO-NPs showed MT production in a dose-related fashion and was found up to 126 and $137 \mu \mathrm{mol} \mathrm{g}^{-1} \mathrm{FW}$, respectively (Fig. 10b). While, CuO-NPs increased MTs maximally by $118 \mu \mathrm{mol} \mathrm{g}^{-1} \mathrm{FW}$ compared to the untreated control $\left(89 \mu \mathrm{mol} \mathrm{g}^{-1} \mathrm{FW}\right)$. ZnO-NPsamended agar also induced MT production in S. lycopersicon up to $114 \mu \mathrm{mol} \mathrm{g}^{-1} \mathrm{FW}$, whereas, soaking treatment increased MTs up to $89 \mu \mathrm{mol} \mathrm{g}^{-1} \mathrm{FW}$ over the untreated control (Fig. 10c). $M$. sativa seedlings treated with CuO-NPs and ZnO-NPs $\left(5 \mathrm{mg} \mathrm{ml}^{-1}\right)$ showed 75 and $79 \mu \mathrm{mol} \mathrm{MTs}{ }^{-1}$ FW (Fig. 10d). Moreover, ZnOBP-treated $R$. sativus, C. sativus, S. lycopersicon, and M. sativa

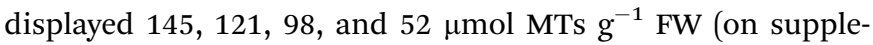

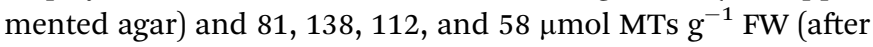
soaking), respectively (Fig. 11a, b, c and d). The role of MTs has been proposed in ROS scavenging where bound metals are released from the MT molecule and in turn ROS species bind to the cysteine (Cys) residue of the same. ${ }^{47}$ For normal cellular functioning, $\mathrm{Zn}$ mobilization from one $\mathrm{Zn}$ binding site to 
another is required, which may either constitute a general pathway by which $\mathrm{Zn}$ is distributed in the cell or be restricted to tackle oxidative stress. ${ }^{48}$ It has been reported that as many as 18 different metals may associate with MTs. ${ }^{46}$ Heavy metals are known to generate oxidative stress, damage cellular membranes and DNA, and disrupt cellular homeostasis. ${ }^{49}$ In the first line of defense, plants have strategies that prevent or reduce the uptake of metal ions by the apoplast by binding them to the cell wall or to cellular exudates, or by inhibiting long-distance transport. ${ }^{50}$ In contrast, when present at elevated concentrations, cells activate a complex network of detoxification tactics, such as chelation of metal ions with MTs in the cytosol and vacuolar sequestration by vacuolar transporters called compartmentalization. ${ }^{51}$ High thermodynamic and low kinetic stability are the main features of the metal-MT complex lagging behind a part of the metal which can be exchanged for other proteins. $^{48}$

In a study by Yang et al., genes responsible for metal homeostasis were found to be up regulated in wheat shoots grown in the presence of $\mathrm{ZnO}$ - and CuO-NPs. ${ }^{52}$ These genes were reported for encoding proteins for metal chelating compounds that might be metallothionein, chemocyanin, and blue-copperbinding proteins. Additionally, a battery of genes for plant defense response was also up regulated. ${ }^{52}$ Based on the toxic impacts exerted by metal oxide species (NPs and BPs) on crop plants, the following sensitivity order is suggested; for $R$. sativus: ZnO-NPs $>$ ZnO-BPs $>$ CuO-NPs $>\mathrm{Al}_{2} \mathrm{O}_{3}$-NPs $>\mathrm{TiO}_{2}$-NPs $>$ CuO$\mathrm{BPs}>\mathrm{Al}_{2} \mathrm{O}_{3}$-BPs $\sim \mathrm{TiO}_{2}$-BPs; C. sativus: $\mathrm{ZnO}-\mathrm{BPs}>\mathrm{ZnO}-\mathrm{NPs}>$ CuO-NPs $>$ CuO-BPs $>\mathrm{TiO}_{2}-\mathrm{NPs}>\mathrm{Al}_{2} \mathrm{O}_{3}-\mathrm{NPs}>\mathrm{TiO}_{2}-\mathrm{BPs} \sim \mathrm{Al}_{2} \mathrm{O}_{3}-$ BPs; $S$. lycopersicon: $\mathrm{ZnO}-\mathrm{BPs}>\mathrm{ZnO}-\mathrm{NPs}>\mathrm{CuO}-\mathrm{NPs}>\mathrm{Al}_{2} \mathrm{O}_{3}-\mathrm{NPs}$ $>\mathrm{TiO}_{2}-\mathrm{NPs}>\mathrm{CuO}-\mathrm{BPs}>\mathrm{Al}_{2} \mathrm{O}_{3}-\mathrm{BPs} \sim \mathrm{TiO}_{2}-\mathrm{BPs}$; and $M$. sativa: ZnO-NPs $>$ CuO-NPs $>$ ZnO-BPs $>\mathrm{Al}_{2} \mathrm{O}_{3}-\mathrm{NPs}>\mathrm{TiO}_{2}-\mathrm{NPs}>\mathrm{TiO}_{2}-$ $\mathrm{BPs} \sim \mathrm{CuO}-\mathrm{BPs} \sim \mathrm{Al}_{2} \mathrm{O}_{3}$-BPs.

\section{Conclusion}

In conclusion, heavy metal oxide NPs as a whole reduced the relative seed germination and root and shoot tolerance indices of plants. Adsorption of MONP aggregates on seeds was significant and followed a dose-dependent uptake in both sets of treatments. Heavy MONPs of $\mathrm{TiO}_{2}, \mathrm{ZnO}, \mathrm{Al}_{2} \mathrm{O}_{3}$, and $\mathrm{CuO}$ formed agglomerates ranging from 148 to $248 \mathrm{~nm}$ in growth media. Plants' dual responses that varied among MONPs and BPs were correlated to the concentrations tested. Among all test species, bulk and NPs of ZnO were found extremely detrimental to the measured growth parameters. In contrast, certain concentrations, specifically those of $\mathrm{TiO}_{2}$ and $\mathrm{Al}_{2} \mathrm{O}_{3}$ NPs, facilitated root and shoot elongation. However, how MONPs cause the positive or negative influence is not very clearly understood yet. It can be presumed that the internalized NPs could have been compartmentalized in cellular organs after partial or no transformation in growth medium and intracellular environment. Alternatively, the enhanced gaseous exchange due to the amendment of NPs in compact agar media could promote root and shoot elongation. Nano and bulk species of $\mathrm{ZnO}$ and $\mathrm{CuO}$ were found stimulatory for metallothionein production. Generally, the response of crops to NPs/BPs varied with dose and plant genotypes. Conclusively, the present study demonstrates the possible toxic effects of submicron and nano forms of heavy metal oxides on edible crops, which warrants the need for safe and regulated disposal of industrial/domestic wastes containing heavy MONPs. Also, the use of $\mathrm{Cu}, \mathrm{Zn}, \mathrm{Al}$, and $\mathrm{Ti}$ oxides requires careful monitoring before/after they are discharged into the agro-ecosystems. Henceforth, the quantitative estimation of NPs in edible crops should be considered cautiously before they are supplied to consumers in order to prevent human health problems.

\section{Conflicts of interest}

The authors declare that there are no conflicts of financial or personal interest.

\section{Acknowledgements}

The authors also extend their appreciation to the University Sophisticated Instruments Facility (USIF), Aligarh Muslim University, Aligarh for respective analysis.

\section{References}

1 B. Ahmed, M. S. Khan, Q. Saquib, M. Al-Shaeri, and J. Musarrat, in Phytotoxicity of Nanoparticles, ed. M. Faisal, Q. Saquib, A. A. Alatar and A. A. Al-Khedhairy, Springer, Cham, Switzerland, 2018, pp. 63-102.

2 Z. Yang, J. Chen, R. Dou, X. Gao, C. Mao and L. Wang, Int. J. Environ. Res. Public Health, 2015, 12, 15100-15109.

3 A. Gogos, K. Knauer and T. D. Bucheli, J. Agric. Food Chem., 2012, 60, 9781-9792.

4 M. Rizwan, S. Ali, M. F. Qayyum, Y. S. Ok, M. Adrees, M. Ibrahim, M. Zia-ur-Rehman, M. Farid and F. Abbas, $J$. Hazard. Mater., 2017, 322, 2-16.

5 B. Ahmed, M. S. Khan and J. Musarrat, Environ. Pollut., 2018, 240, 802-816.

6 P. Gajjar, B. Pettee, D. W. Britt, W. Huang, W. P. Johnson and A. J. Anderson, J. Biol. Eng., 2009, 3, 9.

7 J. Hong, C. M. Rico, L. Zhao, A. S. Adeleye, A. A. Keller, J. R. Peralta-Videa and J. L. Gardea-Torresdey, Environ. Sci.: Processes Impacts, 2015, 17, 177-185.

8 V. Rajput, T. Minkina, A. Fedorenko, S. Sushkova, S. Mandzhieva, V. Lysenko, N. Duplii, G. Fedorenko, K. Dvadnenko and K. Ghazaryan, Sci. Total Environ., 2018, 645, 1103-1113.

9 M. A. Siddiqui, R. Wahab, J. Ahmad, N. N. Farshori, Q. Saquib, S. T. Khan, A. M. Al-Salem, J. Musarrat and A. A. Al-Khedhairy, Nanosci. Nanotechnol. Lett., 2017, 9, 573-582.

10 C. García-Gómez, A. Obrador, D. González, M. Babín and M. D. Fernández, Sci. Total Environ., 2018, 644, 770-780.

11 L. Yin, B. P. Colman, B. M. McGill, J. P. Wright and E. S. Bernhardt, PLoS One, 2012, 7(10), e47674.

12 B. Ahmed, M. Shahid, M. S. Khan and J. Musarrat, Metallomics, 2018, 10, 1315-1327. 
13 P. Landa, T. Cyrusova, J. Jerabkova, O. Drabek, T. Vanek and R. Podlipna, Water, Air, Soil Pollut., 2016, 227, 448.

14 A. Rastogi, M. Zivcak, O. Sytar, H. M. Kalaji, X. He, S. Mbarki and M. Brestic, Front. Chem., 2017, 5, 78.

15 K. S. Siddiqi and A. Husen, Nanoscale Res. Lett., 2017, 12, 92.

16 P. Begum, R. Ikhtiari and B. Fugetsu, Nanomaterials, 2014, 4, 203-221.

17 C. W. Lee, S. Mahendra, K. Zodrow, D. Li, Y. C. Tsai, J. Braam and P. J. J. Alvarez, Environ. Toxicol. Chem., 2010, 29, 669675.

18 S. L. Laware and S. Raskar, Int. J. Curr. Microbiol. Appl. Sci., 2014, 3, 749-760.

19 S. G. Wu, L. Huang, J. Head, M. Ball, Y. J. Tang and D. R. Chen, Aerosol Air Qual. Res., 2014, 14, 632-641.

20 M. L. López-Moreno, G. De La Rosa, J. A. Hernández-Viezcas, J. R. Peralta-Videa and J. L. Gardea-Torresdey, J. Agric. Food Chem., 2010, 58, 3689-3693.

21 M. H. Siddiqui and M. H. Al-Whaibi, Saudi J. Biol. Sci., 2014, 21, 13-17.

22 H. Feizi, P. Rezvani Moghaddam, N. Shahtahmassebi and A. Fotovat, Biol. Trace Elem. Res., 2012, 146, 101-106.

23 E. H. Dehkourdi and M. Mosavi, Biol. Trace Elem. Res., 2013, 155, 283-286.

24 S. Raskar and S. L. Laware, Effect of titanium dioxide nano particles on seed germination and germination indices in onion, Plant Sciences Feed, 2013, 3, 103-107.

25 C. Larue, G. Veronesi, A. M. Flank, S. Surble, N. HerlinBoime and M. Carrière, J. Toxicol. Environ. Health, Part A, 2012, 75, 722-734.

26 P. Boonyanitipong, B. Kositsup, P. Kumar, S. Baruah and J. Dutta, Int. J. Biosci., Biochem. Bioinf., 2011, 1, 4-7.

27 M. Haghighi and J. A. Teixeira Da Silva, J. Crop Sci. Biotechnol., 2014, 17, 221-227.

28 R. Zhang, H. Zhang, C. Tu, X. Hu, L. Li, Y. Luo and P. Christie, Environ. Sci. Pollut. Res., 2015, 22, 11109-11117.

29 H. Mahmoodzadeh, R. Aghili and M. Nabavi, Tech. J. Eng. Appl. Sci., 2013, 1365-1370.

30 P. M. G. Nair and I. M. Chung, Biol. Trace Elem. Res., 2014, 162, 342-352.

31 L. Yang and D. J. Watts, Toxicol. Lett., 2005, 158, 122-132. 32 D. Lin and B. Xing, Environ. Pollut., 2007, 150, 243-250.
33 U. Song, M. Shin, G. Lee, J. Roh, Y. Kim and E. J. Lee, Biol. Trace Elem. Res., 2013, 155, 93-103.

34 L. Vittori Antisari, S. Carbone, A. Gatti, G. Vianello and P. Nannipieri, Environ. Sci. Pollut. Res., 2015, 22, 1841-1853.

35 U. Song, H. Jun, B. Waldman, J. Roh, Y. Kim, J. Yi and E. J. Lee, Ecotoxicol. Environ. Saf., 2013, 93, 60-67.

36 M. Ghosh, A. Jana, S. Sinha, M. Jothiramajayam, A. Nag, A. Chakraborty, A. Mukherjee and A. Mukherjee, Mutat. Res., Genet. Toxicol. Environ. Mutagen., 2016, 807, 25-32.

37 C. O. Dimkpa, J. E. McLean, D. E. Latta, E. Manangón, D. W. Britt, W. P. Johnson, M. I. Boyanov and A. J. Anderson, J. Nanopart. Res., 2012, 14, 1125.

38 R. Liu and R. Lal, Sci. Total Environ., 2015, 514, 131-139.

39 Z. Hossain, G. Mustafa and S. Komatsu, Int. J. Mol. Sci., 2015, 16, 26644-26653.

40 D. Lin and B. Xing, Environ. Sci. Technol., 2008, 42, 55805585.

41 K. J. Dietz and S. Herth, Trends Plant Sci., 2011, 16, 582-589. 42 J. L. Gardea-Torresdey, C. M. Rico and J. C. White, Environ. Sci. Technol., 2014, 48, 2526-2540.

43 R. Suriyaprabha, K. A. Sreeja, M. Prabu, P. Prabu and V. Rajendran, BioNanoScience, 2018, 1-9.

44 D. H. Atha, H. Wang, E. J. Petersen, D. Cleveland, R. D. Holbrook, P. Jaruga, M. Dizdaroglu, B. Xing and B. C. Nelson, Environ. Sci. Technol., 2012, 46, 1819-1827.

45 V. Baskar, S. Nayeem, S. P. Kuppuraj, T. Muthu and S. Ramalingam, 3 Biotech, 2018, 8, 362.

46 R. Joshi, A. Pareek and S. L. Singla-Pareek, in Plant Metal Interaction: Emerging Remediation Techniques, 2015, pp. 239-261.

47 V. H. Hassinen, A. I. Tervahauta, H. Schat and S. O. Kärenlampi, Plant Biol., 2011, 13, 225-232.

48 M. K. Hasan, Y. Cheng, M. K. Kanwar, X.-Y. Chu, G. J. Ahammed and Z.-Y. Qi, Front. Plant Sci., 2017, 8, 1492. 49 A. Rizvi and M. S. Khan, Chemosphere, 2017, 185, 942-952.

50 M. K. Hasan, G. J. Ahammed, L. Yin, K. Shi, X. Xia, Y. Zhou, J. Yu and J. Zhou, Front. Plant Sci., 2015, 6, 601.

51 J. Sácký, T. Leonhardt, J. Borovička, M. Gryndler, A. Briksí and P. Kotrba, Fungal Genet. Biol., 2014, 67, 3-14.

52 K. Y. Yang, S. Doxey, J. E. McLean, D. Britt, A. Watson, D. Al Qassy, A. R. Jacobson and A. Anderson, Botany, 2017, 96, 175-186. 